\title{
Size and shape-controlled nanomaterials based on modified polyol and thermal decomposition approaches. A brief review.
}

\author{
LAUDEMIR C. VARANDA ${ }^{1}$, CAIO G.S. SOUZA ${ }^{1,2}$, DANIEL A. MORAES ${ }^{1}$, HERBERT R. NEVES ${ }^{1,3}$, \\ JOÃO B. SOUZA JUNIOR ${ }^{1}$, MONICA F. SILVA ${ }^{1}$, RAFAEL A. BINI ${ }^{4}$, REBECCA F. ALBERS ${ }^{1,5}$, TIAGO L. SILVA ${ }^{1,6}$ \\ and WATSON BECK JUNIOR ${ }^{1,7}$ \\ ${ }^{1}$ Instituto de Química de São Carlos, Universidade de São Paulo/USP, Grupo de Materiais Coloidais, Departamento de \\ Físico-Química, Av. Trabalhador São-carlense, 400, 13566-590 São Carlos, SP, Brazil \\ ${ }^{2}$ Instituto Federal do Paraná/IFPR, Campus Telêmaco Borba, Rodovia PR 160, Km 19.5, Parque Limeira, \\ 84269-090 Telêmaco Borba, PR, Brazil \\ ${ }^{3}$ Instituto Federal Catarinense/IFC, Campus de Araquari, Rodovia BR 280, km 27, Caixa Postal 21, \\ 89245-000 Araquari, SC, Brazil \\ ${ }^{4}$ Departamento de Engenharia de Bioprocessos e Biotecnologia, Universidade Tecnológica Federal do Paraná/UFTPR, Campus \\ Toledo, R. Cristo Rei, 19, 85902-490 Toledo, PR, Brazil \\ ${ }^{5}$ Departamento de Química, Laboratório Interdisciplinar de Eletroquímica e Cerâmicas, Universidade Federal de São \\ Carlos/UFSCar, Rodovia Washington Luis, Km 235, Caixa Postal 676, 13565-905 São Carlos, SP, Brazil \\ ${ }^{6}$ Departamento de Engenharia Química, Universidade Federal de São Carlos/UFSCar, Rodovia Washington Luis, Km 235, Caixa \\ Postal 676, 13565-905 São Carlos, SP, Brazil \\ ${ }^{7}$ Instituto Federal de Santa Catarina/IFSC, Campus de Gaspar, Rua Adriano Kormann, 510, Bela Vista, \\ 89110-971 Gaspar, SC, Brazil \\ Manuscript received on November 11, 2018; accepted for publication on January 14, 2019
}

\begin{abstract}
How to cite: VARANDA LC, SOUZA CGS, MORAES DA, NEVES HR, SOUZA JUNIOR JB, SILVA MF, BINI RA, ALBERS RF, SILVA TL AND BECK JUNIOR W. 2019. Size and shape-controlled nanomaterials based on modified polyol and thermal decomposition approaches. A brief review.. An Acad Bras Cienc 91: e20181180. DOI 10.1590/0001-3765201920181180.
\end{abstract}

\begin{abstract}
Since its inception in 2007, the Colloidal Materials Group, one of the research groups in nanotechnology of the Institute of Chemistry of São Carlos (IQSC) at University of São Paulo (USP) carries out studies related to the development of syntheses methods of nanoparticles and multifunctional nanostructured systems. Our works search new synthesis methodologies that allow high size and shape control of the individual nanoparticles or that compose the nanostructured systems and has as a principle the synthetic approaches based on the modified polyol and thermal decomposition processes. Systems involving nanoparticles have received extensive attention both in the fundamental research and in several technological applications exploring the unique properties presented in nanomaterials. These properties are strongly size- and shape-dependent of the nanoparticles and a large distribution of size or shape implies in a high response dispersion, justifying the intense research for the so-called nanoparticle monodisperse systems. In this review, we present the main aspects to obtain monodisperse nanoparticulate systems, correlating with the synthesis processes used in our group and some of our results in systems involving nanoparticles with magnetic, optical, and electronic properties, as well as some obtained composite materials for different applications.
\end{abstract}

Correspondence to: Laudemir Carlos Varanda

E-mail: lvaranda@iqsc.usp.br

ORCid: https://orcid.org/0000-0002-4671-5787 
Key words: nanoparticles, nanostructured composites, modified polyol process, thermal decomposition method, size and shape control, Colloidal Materials Group.

\section{INTRODUCTION}

In the last decades, the nanomaterials research, mainly nanoparticles or nanocrystals, has been widely intensified in all development stages, from synthesis, characterization, performance and applications, encompassing basic materials like pure metals or metal oxides and complex ones as multifunctional or nanostructured hybrid materials (Lu et al. 2007, Park et al. 2007, Boles et al. 2016, Kovalenko et al. 2015). As extensively mentioned in the works on nanotechnology, interest from both a scientific and a technological point of view comes, respectively, from both to know and explore new and different properties inherent to the nanoscale. These unique properties of nanometer-scale materials have been investigated with its potential innovative applications, for example in energy conversion (Bott-Neto et al. 2017, Chen et al. 2015, Gomez-Marin et al. 2016, Yin et al. 2014, Huang et al. 2015, Lima et al. 2012), environmental remediation and agriculture systems (Dasgupta et al. 2015, Sozer and Kokini 2009), data storage (da Silva and Varanda 2011, Marques et al. 2001, Santos et al. 2008, Varanda et al. 2001, 2002a, b, c, 2004) and biomedicine (Bini et al. 2016, Feng and Liu 2011, Lim and Majetich 2013, Tartaj et al. 2003, Beck et al. 2011a). Effects of quantum confinement and the local energy disorder of surface atoms make the properties of nanoparticles strongly size-dependent (Kovalenko et al. 2015, Rogach et al. 2002). Although this is a notable advantage for the nanomaterial use, it can also be villain considering the uniformity of expected response for the nanostructured system will be as broad as the polydispersity degree $(\sigma)$ regarding the size and shape distributions of the nanoparticles (Hunter 2001). Not less important than the nanoparticles shape and size control, special attention should be given to the homogeneity of both chemical and structural compositions of the individual nanoparticles (Beck et al. 2011b). Thus, the narrow control over the size and shape uniformities of the nanocrystals is the key to obtain the expected response with simultaneous accuracy and precision.

Thereby, synthesis routes to obtain the so-called monodispersed systems, in which $\sigma$ is less than $10 \%$, are essential to fully exploit the potential of nanoparticulated systems (Hunter 2001). Several methodologies based on physical and chemical approaches have been developed and used in the manufacture of shapedand sized-controlled nanocrystals, each one presenting advantages and disadvantages (Gupta and Gupta 2005, Beck et al. 2011a). While physical methods enable scalability, they lack in controlling of its shape and size, whereas it is just the opposite for chemical methods which provide high control over the process, but a small amount of material (Park et al. 2007). Colloidal chemistry-based synthesis methods provide the essential features to synthesize nanocrystals with the required uniformity. Among the diversity of routes via colloidal methods reported, the modified polyol process or thermal decomposition method, as well as their variations have gained prominence. The exceptional uniformity of nanocrystals (shape, size, composition and structural properties) is achieved by controlling the nucleation and growth processes, adjusting experimental conditions (concentration, atmosphere, among others) and using metal precursors in organic solvents with high boiling points in the presence or absence of surfactants. Additionally, extraordinary success has been reported combining the modified polyol process with the hot-injection approach, where one or more precursors are injected into the reaction medium at a temperature above its decomposition temperature leading to instantaneous and homogeneously nucleation. 
Since its inception, our group has been to develop new synthesis routes of nanoparticles and nanostructured materials based on the modified polyol process combining or not the hot-injection approach. In this brief review, we present some of our main results concerning the uniformity control over nanocrystals and nanostructured hybrid materials involving nanoparticles with magnetic, optical, and electronic properties. In the first sections of the review, we show the main aspects of nucleation and growth processes that lead to the effective control over uniformity of the nanocrystals and the main characteristics of the modified polyol process and hot-injection methods. In the following sections, we present results on different systems involving magnetic, optical, and semiconductor nanoparticles, as well as some nanostructured hybrid materials.

\section{STATEMENTS OF NUCLEATION AND GROWTH PROCESSES}

The success to obtain uniform nanoparticle systems depends fundamentally on understanding and separating the nucleation and growth processes during the synthesis. There are excellent reviews in the literature covering theories and mechanisms of nanoparticles nucleation and growth from solutions (Kwon and Hyeon 2011, Finney and Finke 2008a, b), vapor (Zhang et al. 2012) and in solid phase through epitaxial growth (Carbone and Cozzoli 2010). In this section, however, we intend to address the main characteristics of the Classical Theory of Nucleation and Growth described by the LaMer model, called LaMer burst nucleation (Lamer and Dinegar 1950, Lamer 1952), combined with the Ostwald ripening (Ostwald 1900) that describes the nanoparticle growth. We intend to give the reader the fundamentals of these models, leading to an understanding of their importance to synthesize monodisperse nanoparticle systems. The process of nuclei formation can be understood as an aggregation of species in solution (monomers) originating, initially, clusters from these species that can grow until reaching a size where it comes to be considered nuclei, primary particles or seeds. The exact definition of monomers is difficult to generalize because each material can be composed of different "units" like atoms (elementary), anions, cations, or molecules. There are two types of nucleation in solution: (i) homogeneous nucleation, which is carried out throughout the original (parental) solution in a uniformly distributed manner and (ii) heterogeneous nucleation, which occurs in the inhomogeneities of the solution as vessel surface, onto the impurities surface or particles present in the medium, among others. If the nanoparticle nucleation and growth steps in liquid solution are not adequately separated, heterogeneous nucleation can occur with extreme ease, since the monomers can be incorporated onto the previous stable nuclei whereas new nuclei are developing.

Thermodynamic considerations can be used to understand the homogeneous nucleation process in solution (Thanh et al. 2014) considering the process Gibbs energy balance. Initially defined by Mullin (Mullin 2001) and later reformulated by Thanh (Thanh et al. 2014, Burda et al. 2005, Kwon and Hyeon 2011, Park et al. 2007, Nguyen 2013), the model considers the Gibbs energy associated to the nucleus formation reaction ( $\Delta \mathrm{G}_{\mathrm{R}}$ ) as a sum dependent of the surface contribution ( $\Delta \mathrm{G}_{\mathrm{S}}$ ), related to with surface energy ( $\gamma$ ), and the energy associated with particle volume $\left(\Delta \mathrm{G}_{\nu}\right)$, which is proportional to the energy difference between the monomer in the solution and in the bulk crystal. Thus, considering a spherical nanoparticle with radius $r$, the energy for the overall process and the contribution of surface and bulk energies are given by equation (1). The bulk crystal energy $(r \rightarrow \infty)$ depends on the supersaturation of the solution $(S)$, the molar volume of the crystal $(\nu)$, the temperature $(T)$ and the Boltzmann constant $\left(k_{B}\right)$, equation (2). 


$$
\begin{gathered}
\Delta \mathrm{G}_{\mathrm{R}}=\Delta \mathrm{G}_{\mathrm{S}}+\Delta \mathrm{G}_{\nu}=4 \pi \mathrm{r}^{2} \gamma+\frac{4}{3} \pi \mathrm{r}^{3} \Delta \mathrm{G}_{\nu} \\
\Delta \mathrm{G}_{\nu}=\frac{-\mathrm{k}_{\mathrm{B}} \operatorname{Tl}(\mathrm{S})}{\nu}
\end{gathered}
$$

The first term of $\Delta G_{R}$ is always positive because the $\gamma$ values are positive, and the second term is negative values, and $\Delta \mathrm{G}_{\nu}$ favors the nanoparticles formation as higher the monomers supersaturation value ( $S$ ). The behavior of $\Delta G_{R}$, therefore, assumes a maximum value for the Gibbs energy, from which the nucleus becomes stable. Thus, the value of the critical radius $r_{c}$ and the critical energy $\Delta G_{c}$ for the growth of the particles can be obtained through the derivative $\mathrm{d} \Delta \mathrm{G}_{\mathrm{R}} / d r=0$, equation (3) and (4), respectively. The critical radius corresponds to a limit in which the formed cluster can survive in the solution without being re-dissolved. Therefore, clusters formed in the nucleation step with a radius greater than $r_{c}$ become stable nuclei and tend to grow, whereas smaller ones than $r_{c}$ re-dissolve generating free monomers in solution, as shown in the graph of $\Delta \mathrm{G}_{\mathrm{R}}(\mathrm{r})$, Figure 1a. The nucleation rate $(\mathrm{d} \dot{\mathrm{N}} / d t)$, nucleation of $\dot{\mathrm{N}}$ particles in a time $\mathrm{t}$, can also be defined as an equation Arrhenius-type related to $\Delta \mathrm{G}_{\mathrm{c}}$, equation (5), where $\mathrm{A}$ is the pre-exponential factor. A large number of stable nuclei in a short time (high $\mathrm{d} \dot{\mathrm{N}} / d t$ ) leads to the homogeneous nucleation favoring the monodisperse systems formation. Since the conditions are strongly dependent on the supersaturation of monomers in the solution, the monomers concentration needs to be highest to result in high stable nucleation rate and uniform size. Kwon and Hyeon (Kwon and Hyeon 2011) have shown through theoretical simulations that the increase in value from $S=2$ to $S=4$ results in an increase in the nucleation rate of $\sim 10^{70}$.

$$
\begin{gathered}
\mathrm{r}_{\mathrm{c}}=\frac{-2 \gamma}{\Delta \mathrm{G}_{\nu}}=\frac{2 \gamma \nu}{\mathrm{k}_{\mathrm{B}} \mathrm{T} \ln (\mathrm{s})} \\
\Delta \mathrm{G}_{\mathrm{c}}=\frac{4}{3} \pi \gamma \mathrm{r}_{\mathrm{c}}^{2}=\frac{16 \pi \gamma^{3} \nu^{2}}{3\left[\mathrm{k}_{\mathrm{B}} \mathrm{T} \ln (\mathrm{S})\right]^{2}} \\
\frac{\mathrm{d} \dot{\mathrm{N}}}{d t}=\operatorname{Aexp}\left(\frac{-\Delta \mathrm{G}_{\mathrm{c}}}{\mathrm{k}_{\mathrm{B}} \mathrm{T}}\right)=A \exp \left[\frac{16 \pi \gamma^{3} \nu^{2}}{3 \mathrm{k}_{\mathrm{B}}^{3} \mathrm{~T}^{3}(\ln \mathrm{S})^{2}}\right]
\end{gathered}
$$

After the nuclei formation, the nanoparticles growth starts, and two growth processes can be highlighted: the mechanism controlled by reaction (reaction surface) and the controlled by the monomer's diffusion to the particle surface, were the latter is desired because it can lead to the formation of monodisperse particles (Sugimoto 2001). The diffusion Fick first law, equation (6), can be used to describe the flow of monomers from the solution to a particle in a homogeneous medium (Reiss 1951). Concerning a spherical particle, a concentration gradient with spherical symmetry is formed around it. There is, therefore, a flux of monomers ( $\mathrm{J}$ ) that diffuse through this sphere of the concentration gradient and considering the diffusion coefficient ( D), the particle radius ( $r$ ) and concentration ( C) at a distance $x$ from the center of the particle (where $x \geq r$ ):

$$
\mathrm{J}=4 \pi \mathrm{x}^{2} \mathrm{D} \frac{d C}{d x}
$$

Considering the steady-state of solute diffusion, in which $\mathrm{J}$ can be found as constant irrespective to $\mathrm{x}$ and integrating $\mathrm{C}(\mathrm{x})$ from $\mathrm{r}$ to $\mathrm{r}+\delta$, being $\delta$ the distance from the particle surface to the bulk concentration 


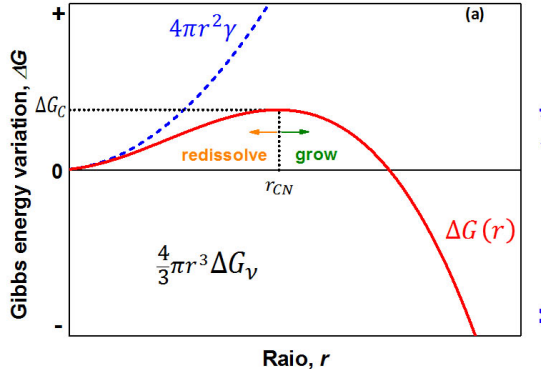

(d)

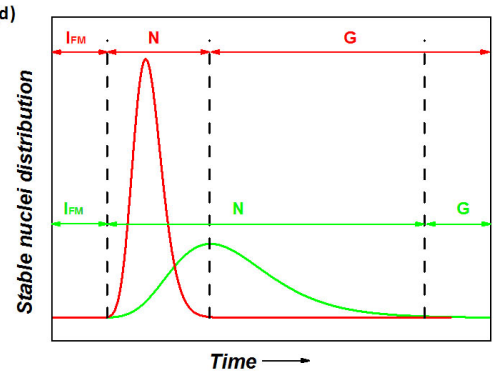

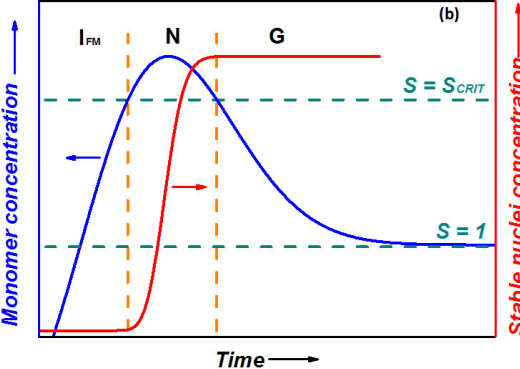

(e)



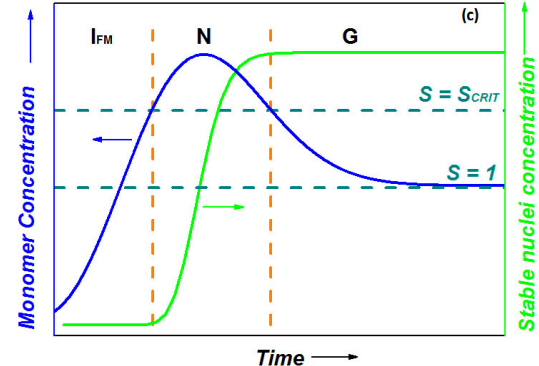

(f)

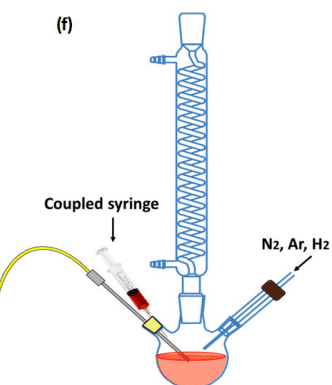

Figure 1 - (a) Schematic Gibbs energy of nucleation and growth processes showing the "critical" behavior. Classical LaMer model diagrams of nucleation and growth according to the time-dependence of monomer and stable nuclei concentrations at (b) fast and (c) slow nucleation process in two monomer supersaturation conditions. (d) Time-dependence of stable nuclei uniformity distribution related to schematic diagrams in (b) and (c). Experimental apparatus using in the synthesis procedures of (e) modified polyol process and thermal decomposition and (f) the hot-injection approach.

of monomers $\left(\mathrm{C}_{\mathrm{B}}\right.$ ), and taking $\mathrm{C}_{\mathrm{S}}$ as the monomers concentration on the particle surface, it is possible to develop the model to obtain the growth rate limited by the monomer diffusion to the particle surface, equation (7) or reaction rate of the monomers on the particle surface, equation (8). $K_{R}$ in equation (8) refers to the surface reaction rate; A complete development of the equations and the model can be found in the literature (Kwon and Hyeon 2011).

$$
\begin{aligned}
& \frac{d r}{d t}=\mathrm{D} \frac{\nu}{\mathrm{r}}\left(\mathrm{C}_{\mathrm{B}}-\mathrm{C}_{\mathrm{S}}\right) \\
& \frac{d r}{d t}=\mathrm{K}_{\mathrm{R}} \nu\left(\mathrm{C}_{\mathrm{B}}-\mathrm{C}_{\mathrm{S}}\right)
\end{aligned}
$$

In general terms, the discussion did not consider the kinetic dependence of the nanoparticle growth with its size. In fact, during the growth, the precipitation and dissolution processes co-occur (Peng et al. 1998). The Gibbs-Thomson relation can be used to modify the equation (7) considering the additional chemical potential due to the curvature radius of a spherical nanoparticle, $\Delta \mu=2 \gamma \nu / \mathrm{r}$. When this potential is combined in equation (7), a general expression for the growth rate of the nanoparticle is obtained, equation (9), based on dimensionless rate, which correlates the degree of supersaturation, $S=\mathrm{C}_{\mathrm{B}} / \mathrm{C}_{\mathrm{S}, e q}^{\circ}$, where the equilibrium surface of the bulk crystal $(r \rightarrow \infty)$ with respect to $\mu^{\circ}$ :

$$
\frac{\mathrm{dr}}{\mathrm{d} \tau}=\frac{\mathrm{S}-\exp \left(1 / \mathrm{r}^{*}\right)}{\mathrm{r}^{*}+\mathrm{K}}
$$

This expression allows defining two dimensionless parameters, the dimensionless radius $\left(\mathrm{r}^{*}\right)$ and the dimensionless time $(\tau)$, respectively, equations (10) and (11). The parameter $\mathrm{K}$ defined in the equation (12) 
relates the type of growth mechanism, where $\mathrm{k}_{\mathrm{g}}$ is a growth rate constant for a flat surface with $\mathrm{r} \rightarrow \infty$ (Talapin et al. 2001). The parameter $\mathrm{K}$ presents values in the range of $10^{-3}$ to $10^{3}$, where $\mathrm{K} \gg 1$ and $\mathrm{K} \ll 1$ are respectively attributed to the growth controlled by reaction and diffusion. The dimensionless growth rate, in turn, indicates under which conditions growth $\left(\mathrm{dr}^{*} / \mathrm{d} \tau>0\right)$ or dissolution $\left(\mathrm{dr}^{*} / \mathrm{d} \tau<0\right)$ of the particle occurs (Talapin et al. 2001).

$$
\begin{gathered}
\mathrm{r}^{*}=\frac{\mathrm{k}_{\mathrm{B}} \mathrm{T}}{2 \gamma \nu} \mathrm{r} \\
\tau=\frac{\left(\mathrm{k}_{\mathrm{B}} \mathrm{T}\right)^{2} \mathrm{DC}_{\mathrm{S}, e q}^{\circ}}{4 \gamma \nu} \mathrm{t} \\
\mathrm{K}=\frac{\mathrm{k}_{\mathrm{B}} \mathrm{T}}{2 \gamma \nu} \frac{\mathrm{D}}{\mathrm{k}_{\mathrm{g}}}
\end{gathered}
$$

The synthesis of a monodisperse nanoparticle system is favored by fast and effective homogenous nucleation (burst nucleation), separating the nucleation and growth stages appropriately so that secondary nucleation does not occur. LaMer mechanism is one of the most commonly used models to represent this behavior (Lamer and Dinegar 1950, Lamer 1952). Accordingly, to the model, there is a high energy barrier to be overcome to promote homogeneous nucleation (Figure 1b and 1c). The LaMer model can be divided into three steps, evaluating the variation of monomers concentration in solution concerning time. In the induction step ( $\mathrm{I}_{F M}$ ), the monomers remain in solution and no precipitation is observed due to the energy barrier, even if the supersaturation condition $(S>1)$ has been reached. At this point, the monomer clusters do not have enough energy to stabilize and are re-dissolved. After the critical saturation $\left(\mathrm{S} \geq \mathrm{S}_{C R I T}\right)$ is achieved, the number of clusters is high enough to overcome the energy barrier and promote the stable nuclei formation, stage $N$ (burst nucleation). The formation of the nuclei leads to a rapid decrease in the free monomer's concentration and when its value becomes lower than $\mathrm{S}_{C R I T}$, no new nuclei formation is observed, the nucleation is effectively stopped, and the growth step $G$ starts.

As shown in Figures $1 \mathrm{~b}$ and $1 \mathrm{c}$, the stable nuclei concentration is related to the elapsed time for the concentration to overcome and, subsequently, to decrease with $\mathrm{S}_{C R I T}$. The faster this process is, the more effective is nucleation, and the formed nuclei present high homogeneity. If the duration of the process is wide enough, nucleation and some growth may occur simultaneously, as shown in Figure 1d. Further, accordingly to Gibbs-Thomson's description, both in nucleation and particle growth processes, dissolutions may occur because of the curvature radius of the formed particles. The Ostwald ripening (Ostwald 1900) model can be used to evaluate this phenomenon, in which smaller particles can be re-dissolved and the monomers released in solution are incorporated onto the larger particles. Thus, long nucleation times may lead to the Ostwald ripening process even during the nucleation step disfavoring the particle uniformity. Finally, monodisperse systems should be favored by faster monomers supersaturation in solution so that the burst nucleation is effective and in the shortest possible period (Baronov et al. 2015).

\section{EXPERIMENTAL APPROACH}

The general experimental apparatus used in all syntheses of polyol and their different approaches are shown in Figures 1e and 1f. The reactants, solvent, surfactants, and polyol are mixed in a three-neck round-bottom 
flask coupled to a Graham condenser. The polyol can be used simultaneously as a solvent and reducing agent (standard polyol method), as only a reducing agent in the modified polyol and thermal decomposition methodologies by using another high boiling point solvent or be absent in some syntheses via thermal decomposition. The second neck is used to introduce different atmospheres into the reaction medium, and the last one is closed with a rubber septum containing the thermocouple that remains immersed into the hot solution also allowing the hot injection via the syringe (Figure 1f). This system is mounted on a hemispherical heating mantle and kept under magnetic stirring by a magnetic stirrer placed below the heating mantle. The temperature, heating rates, and reaction time are assisted by a proportional-integral-derivative (PDI) temperature controller using the thermocouple signal.

The polyol process was initially proposed by Fiévet et al. (1989), by using metal nitrates or chlorides in a diol medium (ethyleneglycol, EG or tetraethyleneglycol, TEG) used as a solvent and reducing agent in the presence of a small amount of $\mathrm{NaOH}$. Monodisperse metal or metal oxide micrometric particles were successfully obtained. Sun et al. $(2000,2001)$ modified the original methodology proposed by Fiévet using a high boiling point solvent and replacing the diol by a long chain polyol (1,2-hexadecanediol) in low concentration. Monodisperse FePt nanoparticles with high crystallinity were synthesized using iron $(0)$ pentacarbonyl and platinum(II) acetylacetonate as metal precursors. However, the control of the chemical composition of the metallic alloy was difficult due to the high volatility of the carbonyl reactant, besides its toxicity. Some modifications were made in the methodology, replacing iron(0) pentacarbonyl by iron(III) acetylacetonate and adjusting the experimental parameters resulting in monodispersed nanoparticles with high-controlled chemical composition and low toxicity reactants uses (Beck et al. 2011b, Santiago et al. 2007, Varanda and Jafelicci 2006, Varanda et al. 2007). There is no clear division in the literature concerning the terms "modified polyol process" and "thermal decomposition". In general, the modified polyol process term has been applied when the polyol is the reducing agent, but not the solvent. In counterpart, thermal decomposition has been widely used for systems that also use high boiling point solvents where one of the reactants behaves as a reducing agent both in the presence and absence of a polyol.

The significant advantage of both methodologies is the use of high boiling point solvents and organometallic precursors in the presence or absence of surfactants that could favor the control of nanoparticles size (Kwon and Hyeon 2008, Park et al. 2007, Beck et al. 2011a, b). The compounds used as precursors generally have good solubility in the synthesis solvent and relatively high thermal stability. When the system reaches the proper temperature, the precursor decomposes quick and homogeneously throughout the bulk solution. The monomers concentration drastically increases in the reaction medium reaching the $\mathrm{S}_{C R I T}$ level. Furthermore, either the solvent or surfactants present in the reaction medium can act as coordinating agents improving the availability and dispersibility of the metal ions in solution narrow the temperature range in which thermal decomposition occurs, that might be little broad due to inhomogeneities such as temperature gradient or hot spots into the reaction medium.

The thermal decomposition of the precursors and, consequently, the increase of the monomer concentration and the formation of stable nuclei can be even more efficient and homogeneous using the hot-injection procedure. In this approach, one or more precursors are injected into the reaction medium at higher temperatures than expected to promote their thermal decomposition. The concentration of monomers becomes higher than the $\mathrm{S}_{C R I T}$ nearly instantaneously, leading to the uniform nucleation in a very short time interval. The concentration of free monomers remains high enough to promote uniform growth of stable nuclei, resulting in highly monodisperse systems with a degree of polydispersity $\sigma \leq 5$ (Donega et al. 2005). 
The nanoparticles synthesized by these methodologies exhibit excellent dispersibility in nonpolar solvents due to the molecules that remain anchored or chemically bound onto their surface, giving them a hydrophobic character. This characteristic is often treated as a disadvantage of the methods when employability requires water-dispersibility behavior as in environmental and biomedical applications. However, the literature has reported several procedures to exchange ligands resulting in nanoparticles with a modified surface, enabling hydrophilic character and dispersibility in water (Neves et al. 2016).

\section{SOME RESULTS IN THE NANOPARTICLES SYNTHESIS IN OUR GROUP}

\section{NANOPARTICLES WITH MAGNETIC PROPERTIES}

Magnetic nanoparticles have been extensively studied due their potential applications in magnetic recording (John et al. 2017, Ohkoshi et al. 2016), as tumor-targeting materials (Borroni et al. 2017, Akal et al. 2016), and in diagnosis as contrast agents in Magnetic Resonance Imaging (MRI) (Iqbal et al. 2015, Yoffe et al. 2013). In each of these applications, nanoparticles response to the magnetic field is strongly affected by their composition, structure, size, shape and size distribution, requiring that nanoparticles syntheses lead the formation of homogeneous material ( $\mathrm{Wu}$ et al. 2016a). Here we describe the syntheses and contributions of our group, and related literature, of magnetic nanoparticles of metal oxides, metals and metal alloys that have strong size- and shape-dependent magnetic behavior.

Iron-based oxides have been developed for tumor-targeting materials, diagnosis as contrast agents, and as a multifunctional platform for new materials (Vallabani and Singh 2018). The magnetic properties of the nanoparticles are size-dependent, and the organic phase syntheses allow metal atoms to be homogenously nucleate, avoiding the simultaneous nucleation and growth (Wu et al. 2016a). In this context, we investigated the influence of the nature of reducer diol in magnetite nanoparticles synthesis based in modified polyol process (Beck et al. 2011b), by thermal decomposition of iron(III) acetylacetonate using different polyols, and also in its absence. The syntheses were carried out adding iron(III) acetylacetonate, oleic acid, oleylamine and $15 \mathrm{~mL}$ of benzyl ether in a three necked-flask, and heating the system to reflux for an hour. This procedure was repeated, adding as diol 1,2-dodecanediol, 1,2-tetradecanediol, or 1,2-hexadecanediol, which allowed to evaluate how diol hydrocarbon chain could influence nanoparticles morphology (Figure 2). Nanocrystals synthesized using 1,2-hexadecanediol showed spherical shape and size around $5 \mathrm{~nm}$ (Figure 2a). Replacing the diol by 1,2-tetradecanediol, nanoparticles shape became faceted and average size increased up to $20 \mathrm{~nm}$, as showed in Figure 2b. When 1,2-dodecanediol was used, similar faceted nanoparticles were observed, however the size of nanoparticles increases to around $40 \mathrm{~nm}$ (Figure 2c). Even in the absence of diol, nanoparticles presented high crystallinity, but the synthesis without diol in benzyl ether led the formation of nanoparticles with morphological features like nanoparticles synthesized using 1,2-tetradecanediol (Figure 2d). The syntheses carried out by thermal decomposition approach in diol absence, at a higher temperature, $315{ }^{\circ} \mathrm{C}$ and $340{ }^{\circ} \mathrm{C}$, respectively, by using 1-octadecene and docosane resulted in monodispersed systems of spherical nanoparticles, as presented in the Figure $2 \mathrm{e}$ and $2 \mathrm{f}$, respectively.

The magnetic properties are correlated with its morphologies as showed in the magnetic hysteresis loop in Figure $2 \mathrm{~g}$, indicating that the synthesized samples without diol and using 1,2-dodecanediol presented saturation magnetization $\left(M_{S A T}\right)$ near $70 \mathrm{emu} \mathrm{g}^{-1}$, which is near the magnetization of bulk magnetite (Ozkaya et al. 2009). However, for smaller particles, synthesized with 1,2-tetradecanediol and 
1,2-hexadecanediol, $M_{S A T}$ was near $60 \mathrm{emu} \mathrm{g}^{-1}$ and $40 \mathrm{emu} \mathrm{g}^{-1}$, respectively, which can be associated not only with nanoparticles size, in smaller ones there are a large number of residual surfactants, that contribute to samples mass, but do not respond to magnetic field. The sample with the largest nanoparticles presented the highest coercivity, around $150 \mathrm{Oe}$, while the sample with the smallest nanoparticles has coercivity near $40 \mathrm{Oe}$. These results agree with the expected for single-domain nanoparticles, in which the coercivity is proportional to nanoparticles volume ( $\mathrm{Li}$ et al. 2017). Our results show that in this experimental method, nanoparticles morphology is strongly dependent on diol and solvent nature, as well as the final reaction temperature.

Metal oxide nanoparticles are the most representative inorganic nanoparticles for biomedical applications since superparamagnetic iron oxide nanoparticles (SPIONs) were first reported as a potential MRI contrast agent (Dias and Lauterbur 1986, Yoffe et al. 2013). However, commercially available SPION-based contrast agents are non-monodisperse and present large hydrodynamic diameter, and can be confused with bleeding, calcification of metal deposits in $T_{2}$-weighted MRI (Zeng et al. 2018). An approach to overcome the drawbacks of SPIONs is the development of nanomaterials that present potential to act as $\mathrm{T}_{1}$-contrast agent, such as ultra-small ferrites nanoparticles (Wei et al. 2017) and $\mathrm{MFe}_{2} \mathrm{O}_{4}$-doped nanoparticles, where $\mathrm{M}$ is two plus cations like Co, Mn, Zn and/or Ni (Lee et al. 2007).

In our group, ultra-small metal oxide nanoparticles were synthesized by the polyol, thermal decomposition or hot-injection methods, which enable to control nanoparticles size, shape, and chemical composition. Manganese ferrite nanoparticles were synthesized in high boiling point solvents, such as benzyl ether, in the presence of 1,2-dodecanediol, oleic acid, and oleylamine. In this approach manganese(II) and iron(III) acetylacetonates, $\mathrm{Mn}(\mathrm{acac})_{2}$ and $\mathrm{Fe}(\mathrm{acac})_{3}$ respectively, were heated to $200{ }^{\circ} \mathrm{C}$ for $60 \mathrm{~min}$, and later heated to boiling point for $120 \mathrm{~min}$, promoting the formation of ultra-small manganese ferrite nanoparticles with average size below $4.0 \mathrm{~nm}$, Figure $3 \mathrm{a}$. However, the temperature plateau at $200{ }^{\circ} \mathrm{C}$ makes difficult to control nanoparticles nucleation and growth, since $\mathrm{Fe}(\mathrm{acac})_{3}$ decomposes in temperature around $180{ }^{\circ} \mathrm{C}$, while $\mathrm{Mn}(\mathrm{acac})_{2}$ decomposition occurs only above $250{ }^{\circ} \mathrm{C}$ (Vonhoene et al. 1958). Moreover, samples synthesized in this method are not monodisperse, and heating-up directly to the boiling point does not solve the problem, because it avoids the incorporation of $\mathrm{Mn}$ (II) into inverse spinel structure of magnetite, leading to poor control over both chemical composition and size distribution (Figure 3b). Besides heating-up syntheses enable to obtain a considerable diversity of nanomaterials, from metals alloys, oxides, to semiconductors (van Embden et al. 2015), to synthesize monodisperse nanomaterials, precursors thermal decomposition should occur in the same range of temperature, which avoids a secondary nucleation to happen while nuclei are growing in solution (Song et al. 2007). When precursors thermal decomposition cannot be managed to prevent simultaneous nucleation and growth, a useful approach is the injection of at least one or both precursors only after the system reaches boiling temperature. The injection of the precursors promotes burst nucleation and provides nanomaterials with rigid control over size, shape, and size distribution (Zacharaki et al. 2016). Because Fe(acac) 3 decomposition occurs in lower temperature than $\mathrm{Mn}(\mathrm{acac})_{2}$, the first was dissolved in about 2-3 $\mathrm{mL}$ of solvent and heated to $80{ }^{\circ} \mathrm{C}$ separately, while the $\mathrm{Mn}$ (II) precursor, 1,2-dodecanediol and surfactants were solubilized in benzyl ether and heated until reaching the boiling temperature. In that point, $\mathrm{Fe}(\mathrm{acac})_{3}$-containing solution was injected into the system and, therefore, the decomposition of both metallic precursors co-occur. This method produces size- and shape-controlled ultra-small manganese ferrite nanoparticles with the average size of $3.8 \mathrm{~nm}$, Figure $3 \mathrm{c}$. The 

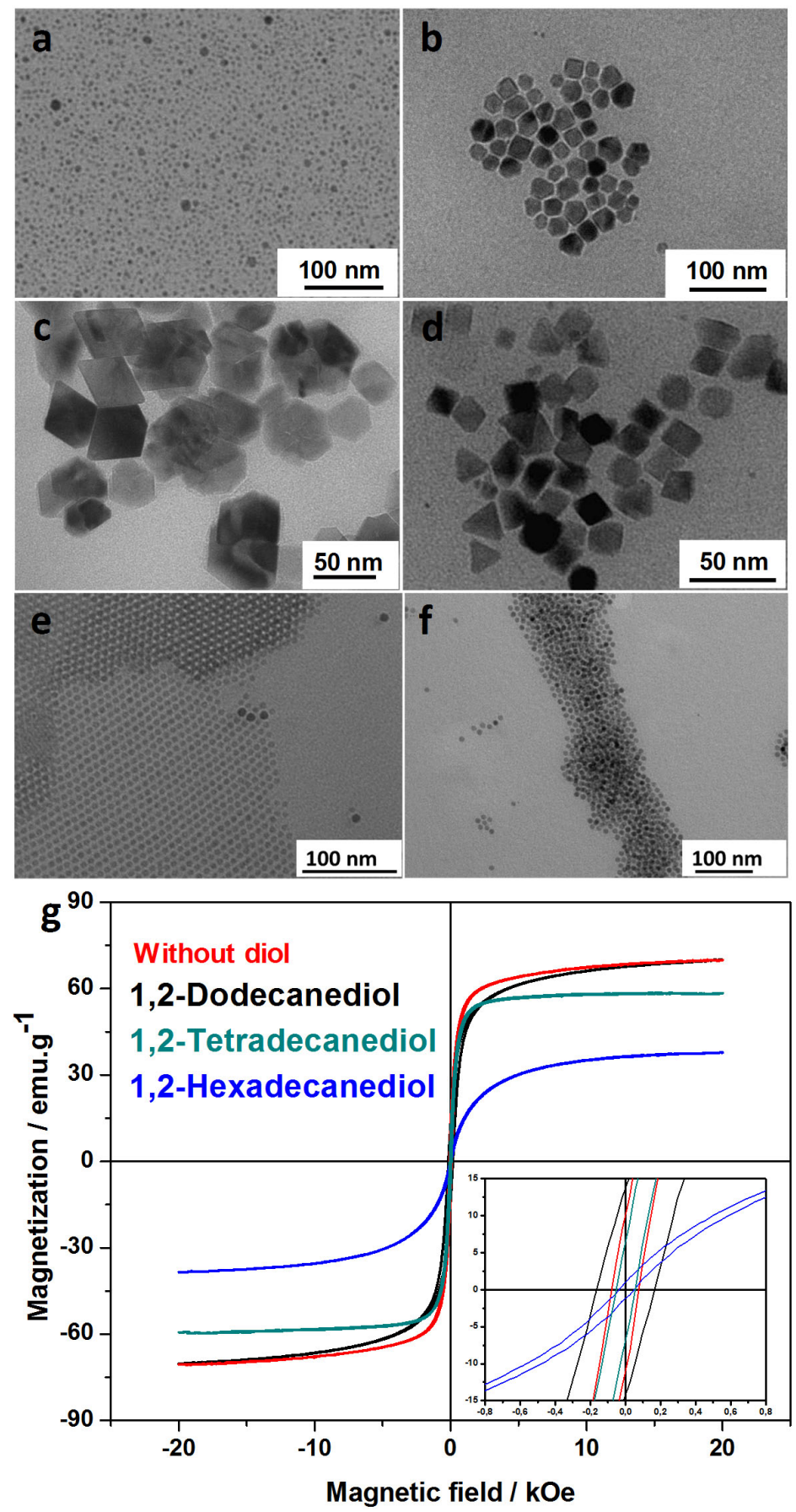

Figure 2 - Transmission electron microscopy (TEM) images of magnetite nanoparticles synthesized via modified polyol process using benzyl ether as the solvent and changing the diol hydrocarbon chain: (a) 1,2-hexadecanediol, (b) 1,2-tetradecanediol, (c) 1,2-dodecanediol and (d) without diol. TEM images of magnetite nanoparticles obtained by simple thermal decomposition method in polyol absence and both different solvent and final temperature: (e) 1-octadecene, $315{ }^{\circ} \mathrm{C}$ (self-assembled) and (f) docosane, $340{ }^{\circ} \mathrm{C}$. (g) Magnetic hysteresis loops at $300 \mathrm{~K}$ of magnetite nanoparticle obtained via the modified polyol process according to the diol nature and TEM images shown in (a-d). 
hot-injection method also leads to greater incorporation of $\mathrm{Mn}(\mathrm{II})$ in the structure, which was confirmed by Energy Dispersive X-Ray and Atomic Absorption spectroscopies.

Following the same approach, we also synthesized mixed ferrites containing $\mathrm{Mn}$ (II) and $\mathrm{Co}$ (II) with average sizes from 4.0 to $6.5 \mathrm{~nm}$, Figure 3d-g. In mixed ferrites, the presence of both Mn(II) and Co(II) contributed to nanoparticles morphology and magnetic behavior. For both manganese and mixed ferrites, nanoparticles composition do not present the expected ratio of $\mathrm{M}(\mathrm{II}) / \mathrm{Fe}(\mathrm{III})$ (where $\mathrm{M}$ is the divalent metal) for stoichiometric composition, as a result of partial reduction of $\mathrm{Fe}$ (III) to $\mathrm{Fe}$ (II) during reaction and consequent competition of $\mathrm{M}$ (II) and Fe(II) for octahedral sites in the structure. Moreover, nanoparticles magnetic behavior was strongly affected by composition and size distribution. In samples with reduced control on nanoparticles size, saturation magnetization is lower than for samples with a narrow size distribution, and this variation of saturation magnetization can be considered a consequence of the size distribution enlargement, as indicated in Figure 3h. Furthermore, mixed ferrites with the proportion of $\mathrm{Mn}(\mathrm{II}): \mathrm{Co}(\mathrm{II})$ of $1: 1$ and 1:2, nanoparticles presented better control over morphology than samples with the proportion of $1: 3$ and 1:5.
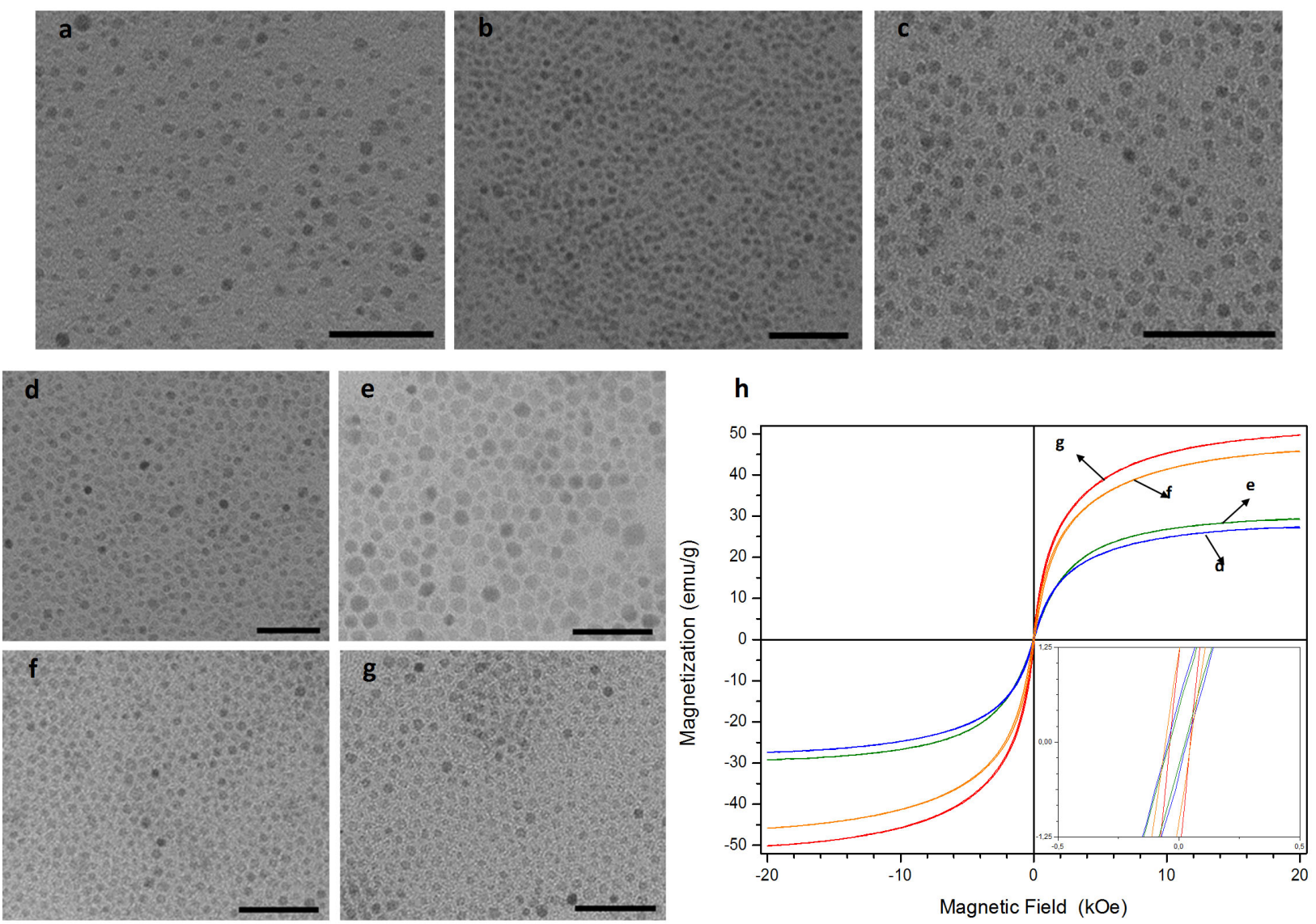

Figure 3 - TEM images of ferrite nanoparticles synthesized by the thermal decomposition method. $\mathrm{MnFe}_{2} \mathrm{O}_{4}$ ferrites at different experimental heating conditions: (a) plateau at $200{ }^{\circ} \mathrm{C}$ before reflux, (b) without plateau (heating-up reflux), and (c) using the hot-injection approach. $\mathrm{Co}_{(1-\mathrm{x})} \mathrm{Mn}_{\mathrm{x}} \mathrm{Fe}_{2} \mathrm{O}_{4}$ mixed ferrite with manganese ratio ( $\mathrm{x}$ ) of: (d) 0.5 ; (e) 0.33 ; (f) 0.25 and (g) 0.18 , respectively. (h) Magnetic hysteresis loops at $300 \mathrm{~K}$ of $\mathrm{Co}_{(1-\mathrm{x})} \mathrm{Mn}_{\mathrm{x}} \mathrm{Fe}_{2} \mathrm{O}_{4}$ assigned to nanoparticles showed in (d-g). TEM scale bars indicate $50 \mathrm{~nm}$. 
Nonetheless, manganese-based oxides were also reported as $\mathrm{T}_{1}$-contrast agents in replacement of SPION and had demonstrated significant potential to overcome the drawbacks of current iron-based contrast agents (Hsu et al. 2016). These oxides, mainly $\mathrm{Mn}_{3} \mathrm{O}_{4}$ and $\mathrm{MnO}$, have demonstrated positive $\mathrm{T}_{1}$ contrast for molecular (Baek et al. 2010) and in vivo application in the determination of anatomical brain structures in mice ( $\mathrm{Na}$ et al. 2007). To synthesize $\mathrm{MnO}$ nanoparticles for biomedical applications, the most common synthesis was using Mn-oleate thermal decomposition in high boiling point solvents (Park et al. 2004). Thermal decomposition under inert atmosphere avoids the oxidation of $\mathrm{Mn}(\mathrm{II})$, and the formation of more oxidized phases on nanoparticles surface, what can influence nanoparticles response to a magnetic field (Lee et al. 2002). Recently in our group, MnO nanoparticles were synthesized by a variety of thermal decomposition method (Neves et al. 2016), in which a mixture of oleic acid and oleylamine act as both solvents and surfactants, and samples have average size about $20 \mathrm{~nm}$. After synthesis, nanoparticles surface modification and functionalization with carboxymethyl dextran increases samples water-dispersibility and decreases their toxicity. These nanoparticles presented $r_{1}$, and $r_{2}$ relaxitivity values of 0.44 and $3.45 \mathrm{~s}^{-1}$ $\mathrm{mM}^{-1}$, respectively, and have a relaxitivity ratio considered low $\left(\mathrm{r}_{2} / \mathrm{r}_{1}=7.84\right)$ (Neves et al. 2016), which demonstrated that after functionalization $\mathrm{MnO}$ nanoparticles have great potential to be a candidate as a $\mathrm{T}_{1}$ contrast agent. These results are comparable to other $\mathrm{MnO}$ nanoparticles reported in the literature with different capping agents, such as silica (Schladt et al. 2012) and polyethylene glycol (Na et al. 2007) concerning the magnetite properties and the MRI response as a $\mathrm{T}_{1}$ contrast agent.

Cobalt monoxide $(\mathrm{CoO})$ nanocrystals are promising for functional materials owing to their potential applications based on magnetic (Qi et al. 2016), optical (Lu et al. 2014) and catalytic (Khan et al. 2015) properties. Bulk $\mathrm{CoO}$ materials are antiferromagnetic, but $\mathrm{CoO}$ nanocrystal can exhibit superparamagnetism and weak ferromagnetism (Seo et al. 2005). Either cubic rock-salt phase and wurtzite-type hexagonal phase $\mathrm{CoO}$ nanocrystal have been synthesized with controlled morphologies by several chemical routes, such as nanospheres (Wang et al. 1997), nanorods, pencil-shape nanorods (An et al. 2006) and nanopyramids (Seo et al. 2005). Wang and coworkers produced $\mathrm{CoO}$ nanocrystal with 4-5 nm by oxidation of $\mathrm{Co}_{2}(\mathrm{CO})_{8}$ in toluene in the presence of $\mathrm{Na}(\mathrm{AOT})$ at $130{ }^{\circ} \mathrm{C}$ (Wang et al. 1997). Chaudret and coworkers synthesized cubic $\mathrm{CoO}$ nanoparticles with a size of $\tilde{2} \mathrm{~nm}$ by oxidation of $1.6 \mathrm{~nm}$ Co nanoparticles (Verelst et al. 1999). Rao and coworkers synthesized tetrahedral $\mathrm{CoO}$ nanoparticles with size ranging from 4-18 nm by the decomposition of Co(II) cupferronate in decalin using a solvothermal route (Ghosh et al. 2005). Hexagonal rod and pyramid-shaped and cubic $\mathrm{CoO}$ nanocrystals were synthesized by Park and coworkers using a size- and shape-controlled synthesis based on thermal decomposition of cobalt(III) acetylacetonate in oleylamine (Seo et al. 2005). Hyeon and coworkers synthesized pencil-shaped hexagonal CoO nanorods by thermal decomposition of the Co-oleate complex in octadecene. The shape and size of the nanorods were controlled by changing the precursor concentration and reaction temperature (An et al. 2006). Recently, our research group developed a chemical route to synthesize size- and shape-controlled c-CoO nanocrystal. In this synthesis, cobalt(III) acetylacetonate was decomposed at high temperature using oleyl-alcohol as a solvent, and both oleylamine and oleic acid as surfactants to produce pyramids-like nanoparticles, as shown in the TEM image of Figure 4a. The $\mathrm{CoO}$ nanoparticles were carefully washed with alcohol and a mixture of hexane and a small amount of both oleylamine and oleic acid to prevent the oxidation to $\mathrm{Co}_{2} \mathrm{O}_{3}$ or $\mathrm{Co}_{3} \mathrm{O}_{4}$ phases. The synthesis route developed can also be used to produce other metal transitions and earth-rare oxides, such as samarium oxide species, leading to the formation of ultrathin samarium oxide nanoplates as shown in TEM images of Figure 4b. 

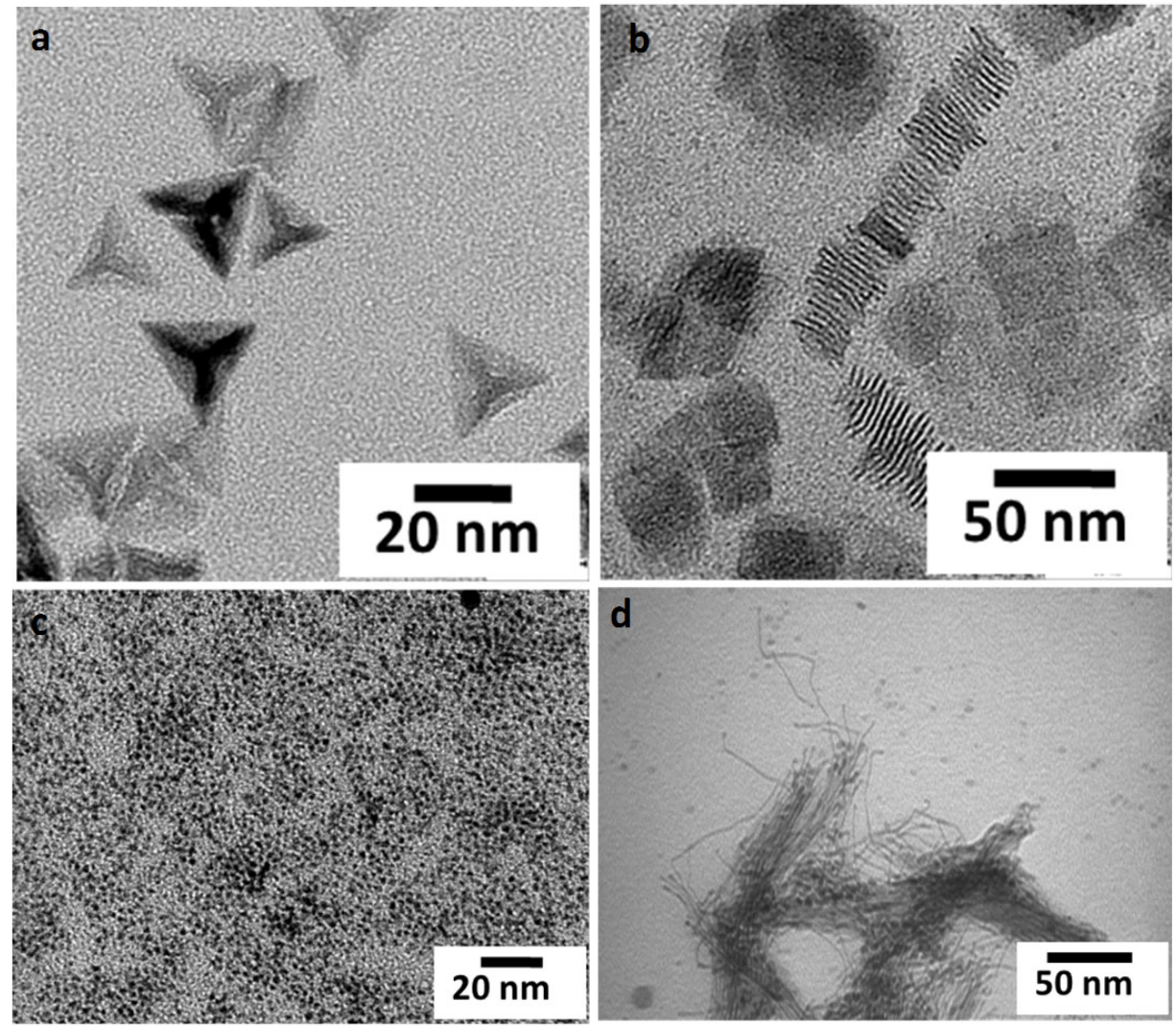

Figure 4 - TEM images of (a) pyramids-like cubic $\mathrm{CoO}$ nanoparticles, (b) samarium oxide nanoplates, (c) ultra-small FePt spherical nanoparticles, and (d) FePt nanowires.

Whereas metal oxides have several methods reported in the literature that leads to right quality nanoparticles, the same does not occur for ferromagnetic materials, mostly 3d-metals, such as Fe, Co, and $\mathrm{Ni}$ (Wu et al. 2016a, Murray et al. 2001). Although the metallic iron has the highest saturation magnetization $\left(M_{S A T}\right)$ among these metals, $222 \mathrm{emu} \mathrm{g}^{-1}$, its oxidation potential is also the highest, what turns the synthesis of iron nanoparticles the most difficult one. As cobalt presents the second highest $M_{S A T}, 166 \mathrm{emu} \mathrm{g}^{-1}$, we also studied new methods that lead to Co nanoparticles with controlled spherical morphology in our group.

Synthesis methods reported in the literature for spherical cobalt nanoparticles frequently uses cobalt precursors in the elementary state. Cobalt pentacarbonyl $\left(\mathrm{Co}(\mathrm{CO})_{5}\right)$ is the preferred precursor, but it is highly unstable, expensive, and makes the synthesis reproducibility challenging to be achieved (Puntes et al. 2001). Another strategy is to use cobalt salts like cobalt chloride, cobalt acetate, or cobalt acetylacetonate due to its volatility at a high temperature of the reaction medium. These precursors require adding a reducing agent to the synthesis to initiate the nanoparticles nucleation and growth, which could make the control over nanoparticles morphology difficult. A modified thermal decomposition method known as hot-injection of the metallic precursor can be used to guarantee a perfect nucleation and growth control essential to produce monodisperse nanoparticles (Kwon and Hyeon 2011). Therefore, our group demonstrates a synthesis procedure that leads to monodisperse spherical cobalt nanoparticles with a diameter below the critic superparamagnetic radius $(<8 \mathrm{~nm})$ and metallic phase was preserved for weeks due to the presence 
of an organic layer of oleic acid (Souza and Varanda 2018). The $M_{S A T}$ of the obtained Co nanoparticles was approximately $30 \%$ higher than the value found for bulk iron oxide materials, however it is worth to mention that nanoparticles frequently display lower magnetization than their respective bulk materials, mainly because it has a large number of atoms on the surface leading to the spins disordering, a phenomenon known as surface anisotropy (Souza and Varanda 2018).

FePt nanoparticles have attracted much attention from the scientific community due to its applications in biomedicine (Souza et al. 2017), catalysis (Guo et al. 2013) and magnetic recording (da Silva and Varanda 2011). Either face-centered cubic $(f c c)$ and face-centered tetragonal $(f c t)$ phases of the FePt nanoparticles are crucial for these applications (Varanda and Jafelicci 2006). The $f c c-F e P t$ nanoparticles are intensely used in biomedicine due to their superparamagnetic properties at room temperature (Hao et al. 2010). Ferromagnetic $f c t$-FePt nanoparticles are one of the most promising materials to high-density magnetic recording, due to the high magnetocrystalline anisotropy of the tetragonal phase (Sun et al. 2000). Our research group has been contributing to the development of the chemical synthesis of FePt nanoparticles since 2007. We showed that iron source of $\mathrm{Fe}(\mathrm{CO})_{5}$, generally used in the synthesis of $f c c$-FePt nanoparticles, can be replaced by iron(III) acetylacetonate in a polyol-derived method known as the modified polyol process, resulting in the composition-controlled synthesis of monodisperse spherical FePt nanoparticles. Different nanostructured superlattices in two and three dimensions were obtained using these as-synthesized $f c c$-FePt nanoparticles (Varanda and Jafelicci 2006). The thermal treatment of these self-assembled FePt nanocrystals at $550{ }^{\circ} \mathrm{C}$ converted the $f c c$ phase to $f c t$ phase, leading to ferromagnetic nanoparticles presenting large coercivity $\left(H_{C}=\right.$ $11.1 \mathrm{kOe}$ ) (Varanda et al. 2007). We studied the mechanism of formation of the mentioned synthesis in 2011, showing that firstly Pt nuclei are obtained by reduction of platinum acetylacetonate using hexadecanediol, then Fe clusters species provide from thermal decomposition of iron(III) acetylacetonate heterocoagulate onto Pt nuclei surface. These Pt nuclei act as a heterogeneous catalyst in a CO-spillover process, which contribute to complete reduction of Fe cluster species, leading to well-controlled composition and narrow compositional distribution (Beck et al. 2011b).

The shape-controlled synthesis of FePt has also been reported for improvement of textural and magnetic alignment for magnetic media application. Nanocubes (Chen et al. 2006), nanorods and nanowires (Wang et al. 2007, da Silva and Varanda 2011) have been synthesized due to their anisotropic structures. Wang and coworkers reported the synthesis of $f c c$-FePt nanorods and nanowires by using the solvent octadecene, oleylamine as both surfactant and a reducing agent, and iron $(0)$ pentacarbonyl as the iron source. The thermal treatment of these nanoparticles led to the loss of shape and substantial coalescence of the one-dimensional nanoparticles (Wang et al. 2007). In 2011, we developed a similar shape-controlled synthesis of FePt nanorods with the size of $\tilde{6} 0 \mathrm{~nm}$ and diameter of 2-3 $\mathrm{nm}$ using iron(III) acetylacetonate as the iron source by a temperature-mediated process. FePt nanorods were obtained partially in $f c t$ phase, leading to the formation of perpendicularly self-assembled $f c t$-FePt ferromagnetic nanorods with a high coercivity (10 kOe) and magnetic alignment (da Silva and Varanda 2011). We have also studied the use of other iron sources and we have observed that the iron precursor influences the size and shape $f c c$-FePt nanoparticles, leading to ultra-small FePt nanospheres and nanowires, respectively, by using benzoylferrocene and diiron nonacarbonyl in a similar method of synthesis, as shown in the TEM images of Figures $4 \mathrm{c}$ and $4 \mathrm{~d}$, respectively. 


\section{NANOPARTICLES WITH OPTICAL PROPERTIES}

The use of colloidal gold nanoparticles is reported since fourth century A.D. by the presence in the Lycurgus Cup, a Roman vessel that has red-green dichroism, although in this epoch the origin effect was not known (Freestone et al. 2007). The first studies about colloidal gold nanoparticles presenting optical properties arose with the initial evaluations of Michael Faraday in the 1850s decade (Faraday 1857). A high number of studies have been developed, aiming to understand the properties, morphological control in syntheses and applications in several areas. The evolution of the scientific theories and technology allowed elucidating the origin of the optical property, which is called Localized Surface Plasmon Resonance (LSPR), observed for noble metals nanoparticles, as gold and silver. This phenomenon arises from the coherent oscillations of conduction electrons of nanomaterials induced by radiation interactions, which is tunable by controlling the different parameters of designing the material, such as size, shape, and dispersant environment. (Kelly et al. 2003, Amendola et al. 2017).

Several syntheses routes can be found in literature in aqueous or organic media using different reducing and surface agents. In our group, we explored several methodologies of syntheses and established some protocols to obtain specific nanoparticles features aiming to tune plasmon band from shape control or distinct metal compositions, to facilitate surface functionalization by using a different surface agent and controlling size dispersion or by using adequate surfactants and adjusting kinetics parameters.

Gold nanoparticles were also used as a color agent in microfluidic immunoassay for detection of Canine Distemper Virus (CDV) (Mazzu-Nascimento et al. 2017), two aqueous routes to obtain gold nanoparticles were reported based on Turkevich's method (Kimling et al. 2006) and Martin's method (Martin et al. 2010), resulting in spherical nanoparticles with 17.3 and $5.4 \mathrm{~nm}$, respectively. In both syntheses, nanoparticles presented negatively charged surface, owing to carboxylate and hydroxy-amino anions present in the surface. Due to the charged surface and colloidal stability exhibited by these colloidal nanoparticles, the conjugation by physical adsorption between AuNPs and anti-CDV antibodies was enabled, resulting in a versatile and straightforward colorimetric assay for CDV diagnosis.

As mentioned in the Experimental Approach section, to achieve low size distribution and higher yield, we used oleylamine as reducing and surface agent, based on previous work described in the literature (Hiramatsu and Osterloh 2004, Liu et al. 2011). These methods allowed to proceed with high gold salts concentration in the synthesis and resulted in high-controlled size dispersion. In Figure 5a, nearly monodisperse gold nanoparticles are shown, with an average diameter of $9.0 \mathrm{~nm}$ and polydispersity degree of $8.2 \%$, which presented a plasmon band centered in $520 \mathrm{~nm}$. Also, we synthesized silver nanoparticles by oleylamine-mediated synthesis, and unlike gold that nanoparticles were formed at $80{ }^{\circ} \mathrm{C}$, no nanoparticles formation after two hours at this temperature. However, when the temperature was increased to $120{ }^{\circ} \mathrm{C}$, leads to nanoparticles exhibiting plasmon band centered in $420 \mathrm{~nm}$, with poor control over the size since the average diameter was $6.9 \mathrm{~nm}$ and the polydispersity degree of $26.5 \%$, Figure $5 \mathrm{~b}$. The distinct control over size nanoparticles when comparing gold and silver can be attributed to the higher reduction potential exhibited by $\mathrm{Au}^{3+}$ than $\mathrm{Ag}^{+}$. Thus a lower temperature is required to reduce $\mathrm{Au}^{3+}$ to $\mathrm{Au}$, resulting in a faster nucleation step and slower growth process. In the case of silver, elevated temperature (Cavicchioli et al. 2005), necessary to promote the $\mathrm{Ag}^{+}$to $\mathrm{Ag}$ reduction hinder the separation between nucleation and growth steps because the growth rate is a function of temperature. Thus growth and nucleation steps coincide, leading to a more spread size distribution. 
Nanomaterials with different shapes were also obtained, as ultrathin gold nanowires presenting lengths of micrometers orders and diameter between 1-2 nm, showed in Figure 5c. Gold nanowires and nanospheres were obtained simultaneously, and additional separation process by ultra-centrifuging combining with solvent gradient is needed to promote its separation. When Takata and collaborators studied the optical plasmon band of ultrathin gold nanowires synthesized approaching other routes, and showed the materials presented plasmon band resonance absorption in the Mild-IR and Far-IR (Takahata et al. 2014). Besides Wang and collaborators (Wang et al. 2008) showed that similar ultrathin gold presented excellent electrical conductivity and Kraus's group, reported applications in electrical nanodevices (Gonzalez-Garcia et al. 2016, Maurer et al. 2015, 2016). We investigated $\mathrm{Cu}_{3} \mathrm{Au}$ nanorods (Figure 5d) and nanospheres (Figure $5 \mathrm{e})$, cheaper than gold nanomaterials, but presenting the similar optical property. The nanospheres presented only one plasmon band absorption, whereas nanorods presented two plasmon band resonance, attributed to longitudinal and transversal plasmon resonance, Figure $5 \mathrm{f}$. The optical behavior is already well known, and these results open possibilities to applications, such as in therapies and diagnosis (Yin et al. 2017, Rauta et al. 2018, Nair et al. 2018).

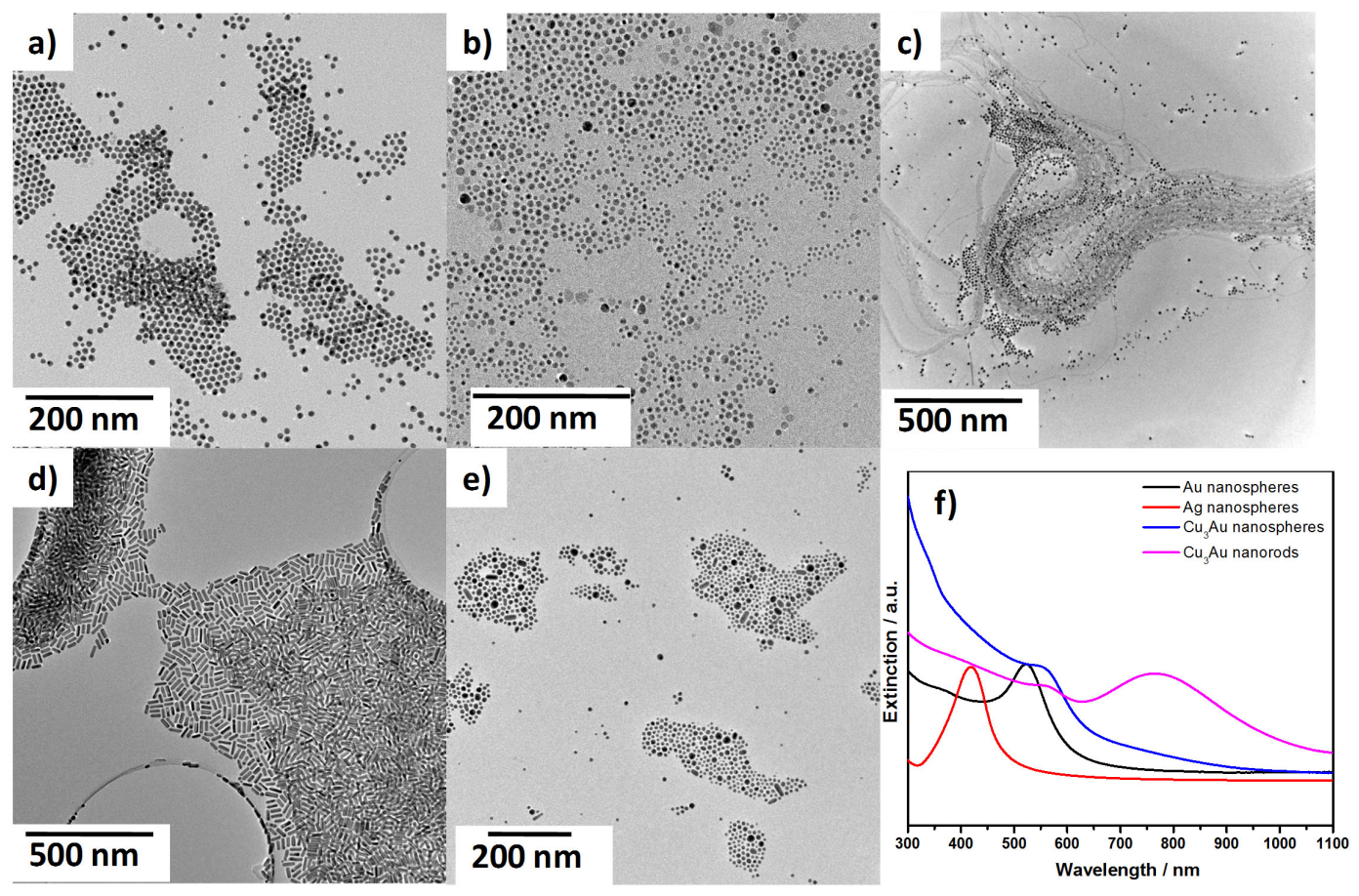

Figure 5 - TEM images of (a) Au nanospheres, (b) Ag nanospheres, (c) ultrathin $\mathrm{Au}$ nanowires, (d) $\mathrm{Cu}_{3} \mathrm{Au}$ nanorods, and (e) $\mathrm{Cu}_{3} \mathrm{Au}$ nanospheres synthesized by thermal decomposition methods. (f) the UV-Vis extinction spectra of $\mathrm{Au}, \mathrm{Ag}, \mathrm{Cu}_{3} \mathrm{Au}$ nanospheres and $\mathrm{Cu}_{3} \mathrm{Au}$ nanorods.

\section{NANOPARTICLES WITH ELECTRONIC PROPERTIES}

Nanoparticles of semiconductor materials display a remarkable property related to the confinement of charge carriers that leads to new electrical and optical characteristics (Alivisatos 1996). Electrons and holes are confined in all three directions for spherical nanoparticles, and these nanomaterials are known as quantum dots (Norris and Bawendi 1996). Among them, the metal chalcogenides as II-VI type like CdSe, CdS, 
CdTe, among others, could be highlighted as the central quantum dots systems studied until now (Murray et al. 1993). However, although the toxicity of cadmium is high for some precursors, most of the synthesis routes available also use reactants that are highly unstable or toxic reactants. Phosphines and phosphoric acids are frequently used as ligands being trioctylphosphine (TOP) and trioctylphosphine oxide (TOPO) the principal reactants in the synthesis of CdSe, a synthesis procedure known in the literature as TOP-TOPO method (Qu et al. 2001). Many efforts in our group have been made to modify or develop new methods that use lower or non-toxic reactants that could lead to spherical II-VI nanoparticles with similar or improved quality. The crystallographic structure, surface oxidation, morphology control, and optical properties are some characteristics that have been investigated in the quantum dots obtained. Ligands like oleic acid and oleylamine are being used and both precursors cadmium and selenium are being replaced compared to the literature to their oxide compounds cadmium oxide $(\mathrm{CdO})$ and selenium oxide $\left(\mathrm{SeO}_{2}\right)(\mathrm{Qu}$ et al. 2001). The modified polyol process and the hot-injection approach have also been applied to improve the quality of CdSe quantum dots. Monodisperse CdSe quantum dots were synthesized, presenting the cubic structure zinc blend and expressive optical properties, such as high color purity (narrow photoluminescence emission peak), controlled size, shape, and emission position, and photoluminescence quantum yields around 0.15. Those characteristics are among the best found in the literature for CdSe quantum dots showing that the quality of the synthesis method studied in the in our laboratory. The synthesis developed is highly reproducible and uses chemicals easily found in laboratories when compared to the typical ones reported in the literature, usually requiring to be stored inside gloveboxes.

CdSe quantum dots presented optical characteristics that enable their application in several technological and biomedical systems (Lia and Zhu 2013, Pietryga et al. 2016). However, surface oxidation and crystallographic defects could generate trap states that decreases their optical and electric performance. The growth of an inorganic shell of another semiconductor material with broader band gap energy is the primary strategy to overcome some of these issues (Dabbousi et al. 1997, Creti et al. 2005). This shell can protect the CdSe core against oxidation and keeps the charge carrier confinement within the core, which improves the probability of radiant recombination and increases the photoluminescence quantum yields. By using a material with lower toxicity, the core/shell nanostructure could present now another feature that enables their application in biomedicine. Among semiconductors with a larger bandgap, $\mathrm{ZnS}$ is an excellent choice as its lower toxicity and composition based in common and inexpensive elements makes the core/shell $\mathrm{CdSe} / \mathrm{ZnS}$. Our results show that the improvement in quantum efficiency and chemical stability allow these systems to be applied as sensors in biomedicine. The core/shell CdSe/ZnS nanostructure contains oleic acid and oleylamine as ligands, which allows perfect colloidal stability in non-polar solvents like hexane and toluene. However, for biomedical applications, efforts must be made to transfer the nanoparticles to water or, more appropriate in physiological solutions, keeping their physical-chemical characteristics and owing good colloidal stability in this environment.

\section{NANOSTRUCTURED COMPOSITES MATERIALS}

Recently, nanostructured composites materials have been developed to obtain new or improved properties. Magnetic nanoparticles have shown potential for different biomedical applications, but these nanoparticles could biodegradation if its surface when exposited to the biological environment. Such problems may be overcome by coating the nanoparticles with biocompatible (polymer or inorganic compounds) or organic 
molecules to stabilize their surface (Vogt et al. 2010, Bloemen et al. 2012). Silica $\left(\mathrm{SiO}_{2}\right)$ is commonly used as an inorganic surface modifier, presenting advantages like hydrophilicity, physical-chemical stability, and relative permeability/biocompatibility, among others. Such features are required to most biomedical applications of magnetic nanoparticles. The dipole-dipole interactions on the silica surface, in addition to its hydrophilic behavior, avoid particles agglomeration, and improve colloidal stability in aqueous solutions. As an additional advantage, the silanol $(\mathrm{Si}-\mathrm{OH})$ groups allow a great versatility of additional functionalization on the silica surface with pharmaceutical drugs and/or biomolecules (Sodipo and Aziz 2016).

Several strategies to modify magnetic nanoparticles surface with silica can be found in the literature. Some examples include gas phase deposition method (Guo et al. 2010, Janzen et al. 2003, Kim et al. 2012, Teleki et al. 2009), modified seed-mediated growth process (Arizaga et al. 2013, Hui et al. 2011), non-seeded silica incorporation (Setyawan et al. 2012, Sodipo and Aziz 2015), sol-gel method (Lu et al. 2002, Deng et al. 2005, Morel et al. 2008), microemulsion based method (Santra et al. 2001, Vogt et al. 2010, Ding et al. 2012). Silica-coated magnetic nanoparticles have been obtained to develop multifunctional nanomaterials, which present unique properties from the conjugation of different types of materials or molecules (Lu et al. 2007, Costi et al. 2010). Our research group has applied variations of the microemulsion method on the coating of FePt, iron oxide, and magnetite-coated FePt nanoparticles with silica. Controlled shell thickness ranging from $5 \mathrm{~nm}$ to $14 \mathrm{~nm}$ were obtained according to the reaction time and the amounts of TEOS and magnetic nanoparticles, as shown for single magnetite core $\left(\mathrm{Fe}_{3} \mathrm{O}_{4} @ \mathrm{SiO}_{2}\right)$ in Figure 6a. Some results using magnetic silica-coated magnetic nanoparticles will be presented later in this section.

One of the main multifunctional nanomaterials reported is luminomagnetic nanoparticles (LMNP) that are nanoparticles with conjugated luminescent and magnetic properties from the conjugation of magnetic nanoparticles and luminescent sensors such as luminescent quantum dots (for example, CdSe) or organic dyes, such as Rhodamine B (RhB) molecules. There are a lot of types of LMNP in different structures and with different luminescent and magnetic materials depending on the desired applications (Cozzoli et al. 2006, Corr et al. 2008). We have recently obtained two different types of luminomagnetic nanomaterials: (1) layer-by-layer of $\mathrm{FePt} @ \mathrm{Fe}_{3} \mathrm{O}_{4} / \mathrm{SiO}_{2} / \mathrm{RhB} / \mathrm{SiO}_{2} \mathrm{LMNP}$ and (2) silica-coated $\mathrm{FePt}-\mathrm{Fe}_{3} \mathrm{O}_{4}$-CdSe heteronanostructures (HNS) (Souza et al. 2013, 2017).

The FePt@ $\mathrm{Fe}_{3} \mathrm{O}_{4} / \mathrm{SiO}_{2} / \mathrm{RhB} / \mathrm{SiO}_{2}$ LMNP was obtained using layer-by-layer approach, where the magnetic core of $\mathrm{FePt} @ \mathrm{Fe}_{3} \mathrm{O}_{4}$ was synthesized via seed-mediated growth method by coating the FePt seeds with a thin magnetite shell, followed by silica coating by reverse micelle. These nanoparticles were annealed to improve the saturation magnetization of the magnetic core coupling the ferromagnetic and ferrimagnetic phases, respectively assigned to FePt and magnetite due to simultaneous atoms diffusion between core and shell. It is noteworthy that the silica layer also protects the magnetic cores from sintering during annealing at temperature up to $550{ }^{\circ} \mathrm{C}$. Rhodamine $\mathrm{B}(\mathrm{RhB})$ luminescent dye was added onto the annealed silica-coated magnetic nanoparticle and coated again with the outer silica shell (Souza et al. 2013). For the silica coating, FePt $@ \mathrm{Fe}_{3} \mathrm{O}_{4}$ magnetic nanoparticles were dispersed in a water-in-oil microemulsion composed of cyclohexane, Igepal ${ }^{\circledR} \mathrm{CO}-520$, and aqueous ammonium hydroxide. The silica layer grows on the surface of the magnetic nanoparticles by the addition of tetraethylorthosilicate (TEOS). Luminescent dye $\mathrm{RhB}$ was incorporated onto the silica-coated nanoparticle surface followed by coating with an outer silica shell in a layer-by-layer structure (Souza et al. 2013) as shown in Figure 6b. The bifunctional LMNP of $\mathrm{FePt} @ \mathrm{Fe}_{3} \mathrm{O}_{4} / \mathrm{SiO}_{2} / \mathrm{RhB} / \mathrm{SiO}_{2}$ showed high water dispersibility, colloidal stability, and hydrophilic surface. TEM images show FePt@ $\mathrm{Fe}_{3} \mathrm{O}_{4} \mathrm{MNP}$ obtained with around $6.0 \mathrm{~nm}$ and $\mathrm{FePt} @ \mathrm{Fe}_{3} \mathrm{O}_{4} / \mathrm{SiO}_{2} / \mathrm{RhB} / \mathrm{SiO}_{2}$ 
LMNP with a diameter around $34 \mathrm{~nm}$ (Figure 6c) and enhanced magnetic properties. The superparamagnetic behavior of $\mathrm{FePt} @ \mathrm{Fe}_{3} \mathrm{O}_{4} / \mathrm{SiO}_{2} / \mathrm{RhB} / \mathrm{SiO}_{2}$ was preserved increasing around ten times the saturation magnetization to $64.3 \mathrm{emu} \mathrm{g}^{-1}$, compared with the pure silica coated-magnetite obtained in the same conditions. Luminescence quenching was minimized because the inner and outer silica layers avoided the contact between dye/magnetic core and dye/solvent, respectively, generating a water-dispersity stable emitter for, at least, one hour (Souza et al. 2013).

Similar microemulsion method was also applied in 2017 to produce silica-coated $\mathrm{FePt} / \mathrm{Fe}_{3} \mathrm{O}_{4}-\mathrm{CdSe}$ heteronanostructures. We have obtained silica-coated FePt- $\mathrm{Fe}_{3} \mathrm{O}_{4}-\mathrm{CdSe}$ luminomagnetic HNS. FePt-Fe ${ }_{3} \mathrm{O}_{4}$ MNP, with high magnetization and superparamagnetic behavior, in which the CdSe quantum dots, with luminescent properties, are conjugated. Moreover, we used micelle-reverse microemulsion route to provide silica coating on HNS surface to provide colloidal stability in aqueous solution and low toxicity for potential biological applications (Souza et al. 2017). The formation of $\mathrm{FePt} / \mathrm{Fe}_{3} \mathrm{O}_{4}-\mathrm{CdSe} \mathrm{HNS}$ was provided using the hot-injection approach in the presence of magnetic seeds, in which selenium precursors were injected in high temperature into the reaction medium with $\mathrm{FePt} / \mathrm{Fe}_{3} \mathrm{O}_{4}$ magnetic seeds, cadmium precursors, oleylamine and oleic acid as the surface agents and an organic solvent. After these steps, $\mathrm{FePt} / \mathrm{Fe}_{3} \mathrm{O}_{4}-\mathrm{CdSe}$ nanomaterials showed hydrophobic behavior, due to the presence of oleic acid and oleylamine on its surface. To provide hydrophilic surface and colloidal stability in aqueous solution, HNS were coated with silica shell using reverse-micelle microemulsion route, used to control the silica coating on HNS surface, since it allows the silica coating in single HNS with controlled thickness, size distribution and morphology of the silica shell on HNS surface, as schematized in the Figure 6d. The hydrophobic FePt/ $/ \mathrm{Fe}_{3} \mathrm{O}_{4}$ nanoparticles showed a diameter of $10.6 \mathrm{~nm}$ with controlled size and morphology. $\mathrm{FePt} / \mathrm{Fe}_{3} \mathrm{O}_{4}-\mathrm{CdSe}$ luminomagnetic HNS with two-particle size each HNS (the smaller particle with higher contrast showed diameter around 2.5 $\mathrm{nm}$, and larger particles with higher contrast showed diameter around $9.0 \mathrm{~nm}$ ), as shown in Figure 6e. After silica coating to provide aqueous dispersibility, silica-coated $\mathrm{FePt} / \mathrm{Fe}_{3} \mathrm{O}_{4}$-CdSe $\mathrm{HNS}$ showed the diameter of $25 \mathrm{~nm}$ with controlled size and morphology, and the silica thickness is around $7 \mathrm{~nm}$ and homogenous distribution on the surface of each HNS. The saturation magnetization $\left(M_{S A T}\right)$ of $\mathrm{FePt} / \mathrm{Fe}_{3} \mathrm{O}_{4}$ pure magnetic core, $\mathrm{FePt} / \mathrm{Fe}_{3} \mathrm{O}_{4}$-CdSe HNS, and silica-coated HNS were 46.8, 24.1 and $11.1 \mathrm{emu} \mathrm{g}^{-1}$, respectively (Souza et al. 2017).

Our work in the group has also directed efforts to synthesize magnetic nanocatalysts. Nanocatalysis is a growing field, which involves the use of nanomaterials in catalysis applications. The use of magnetic nanoparticles in catalysis shows a promising research area since the reduced dimensions of nanoparticles combined to their magnetic properties makes it possible to perform quasi-homogeneous catalytic processes. This approach is merging advantages such as high dispersibility in the reaction medium, high reactivity that results in better yields and easy separation of the reaction medium after the reaction, which is possible by the simple application of an external magnetic field. Several types of a magnetic core coated with the active catalytic layer have been reported (Wei et al. 2011). Some of these catalytic materials include $\mathrm{TiO}_{2}$, $\mathrm{ZnO}$, and CdS semiconductors, which are mainly applied in photocatalysis (Garcia-Garrido et al. 2011, Dehghani et al. 2013). $\mathrm{TiO}_{2}$ is a strong oxidizing with both low cost and toxicity, and because of this widely employed in catalytic systems (Ochiai and Fujishima 2012). However, titanium oxide hybrid materials, for example, titania-coated magnetite, have lower photoactivity when pollutants degradation was compared with pure titania in the same assay conditions. Hence, the present efforts aim to obtain a homogeneous coating maintaining the photocatalytic activity compared to the activity of core-free titania nanoparticles (Yao et al. 
2015). The literature presents some experimental routes to produce titania-coated magnetic nanoparticles. The highlighted reported routes among scientific community are sol-gel method (Chen et al. 2010, Fu et al. 2005), modified sol-gel method (Alvarez et al. 2010, Lee et al. 2006), solid-phase synthesis (Aziz et al. 2013, Tawkaew and Supothina 2008), solvothermal method (Su et al. 2014, Pang et al. 2011) and spray pyrolysis method (Harra et al. 2013).

Magnetite nanoparticles obtained by thermal decomposition method in our research group (Varanda et al. 2008) were initially coated with silica in water-in-oil microemulsion, followed by an outer coating with titanium dioxide (titania) by an acetic acid assisted synthesis previously reported by Chen et al. for the synthesis of titania microspheres (Chen et al. 2010). The interlayer of silica seeks to avoid direct contact between the magnetic and catalytic phases that are reported to decrease $\mathrm{TiO}_{2}$ photoactivity due to magnetite photodissolution and electronic transfer between both phases (Tawkaew and Supothina 2008). Differently from conventional sol-gel methods, in which hydrolysis rates of precursors are fast enough to hinder particles size control, the applied method uses titanium(IV) butoxide and ethylene glycol (EG) to generate an intermediate titanium glycolate phase which undergoes hydrolysis in a further reaction step leading to titanium dioxide particles (Damato et al. 2013). In our experiments, by using titanium(IV) isopropoxide (TIP) as a metal precursor in EG medium, after addition of silica-coated magnetic nanoparticles (SCMNP), the titanium glycolate phase is formed onto silica surface and allows a homogeneous and controlled titania shell after hydrolysis. As shown in the Figure $6 \mathrm{f}$ and $6 \mathrm{~g}$, by controlling the mass ratio $\left(\mathrm{R}_{\mathrm{M}}\right)$ between TIP and SCMNP $\left(\mathrm{R}_{\mathrm{M}}=\mathrm{m}_{\mathrm{TIP}} / \mathrm{m}_{\text {SCMNP }}\right)$, we have succeeded to control the titania shell thickness from $2(\mathrm{R}=6)$ to $12 \mathrm{~nm}(\mathrm{R}=11)$. XRD analysis shows titania is present as anatase crystal phase. The anatase crystallinity was increased after annealing in an $\mathrm{H}_{2}$ atmosphere with temperature up to $250^{\circ} \mathrm{C}$. Annealing also increased the magnetic response of magnetic core due to a partial reduction of magnetite to $\alpha$-iron phase. Photodegradation experiments showed that the annealed sample with $12 \mathrm{~nm}$ titania shell thick exhibit photocatalytic activity similar to $170 \mathrm{~nm}$ pure anatase nanoparticles obtained by the same method, with the additional advantage to be a magnetically recyclable catalyst.

Our research group have also used organic materials for coating or encapsulating nanoparticles. Chitosan is used to encapsulate nanoparticles, essential oils, proteins, drugs, to create a drug delivery carrier in specific conditions (Yoksan et al. 2010, Bernkop-Schnurch and Dunnhaupt 2012). These characteristics are shown in studies that demonstrate that chitosan has biodegradability in many processes, like enzymatic catalysis and $\mathrm{pH}$ variations (Wang et al. 2011, Vivek et al. 2013, Masarudin et al. 2015). We adjust procedures that initially were used to synthesize chitosan nanoparticles (Calvo et al. 1997) to produce nanocapsules of magnetite nanoparticles with surface modification. Ionic gelification is based on ionic interactions of chitosan positive amino groups and negative groups of sodium tripolyphosphate (TPP) (Fan et al. 2012). In order to synthesize nanocapsules with controlled morphology, nanoparticles were added during the steps on reticulation reaction (Khalkhali et al. 2015), based on the previously published work (Calvo et al. 1997). The synthesized magnetite nanoparticles by the modified polyol process in our research group were used in two conditions: coated with dimercaptosuccinic acid (DMSA) (Tartaj et al. 2003) and with the washed surface by hot methanol. Fan et al. published an optimization procedure including modifications on the temperature of the chitosan solution, the concentration of chitosan and TPP solutions. Magnetite nanoparticles were added in chitosan solution stirring in water-bath at $60^{\circ} \mathrm{C}$, and then, TPP solution stirring in ice-bath was quickly added to the system (Fan et al. 2012). In according to Figure 6h, nanostructures in a homogenous system of magnetite nanoparticles $(5 \mathrm{~nm})$ in a chitosan matrix, with a size around $100 \mathrm{~nm}$, using magnetite with DMSA, 


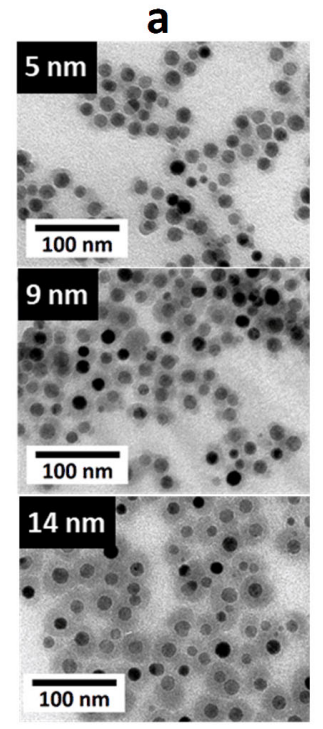

b

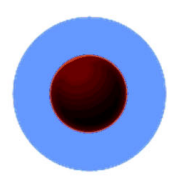

$\mathrm{FePt} @ \mathrm{Fe}_{3} \mathrm{O}_{4} / \mathrm{SiO}_{2}$

d

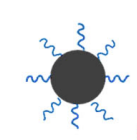
$\mathrm{O}_{4}$

$\mathrm{FePt} @ \mathrm{Fe}_{3} \mathrm{O}_{4}$
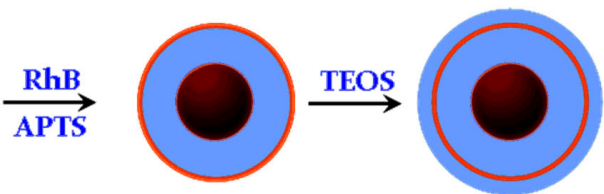

$\mathrm{FePt} @ \mathrm{Fe}_{3} \mathrm{O}_{4} / \mathrm{SiO}_{2} / \mathrm{RhB} \quad \mathrm{FePt} @ \mathrm{Fe}_{3} \mathrm{O}_{4} / \mathrm{SiO}_{2} / \mathrm{RhB} / \mathrm{SiO}_{2}$

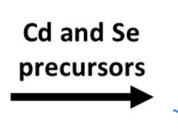

$\mathrm{FePt} @ \mathrm{Fe}_{3} \mathrm{O}_{4} / \mathrm{CdSe}$

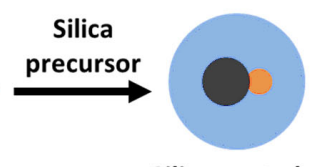

Silica-coated $\mathrm{FePt} @ \mathrm{Fe}_{3} \mathrm{O}_{4} / \mathrm{CdSe} \mathrm{HNS}$
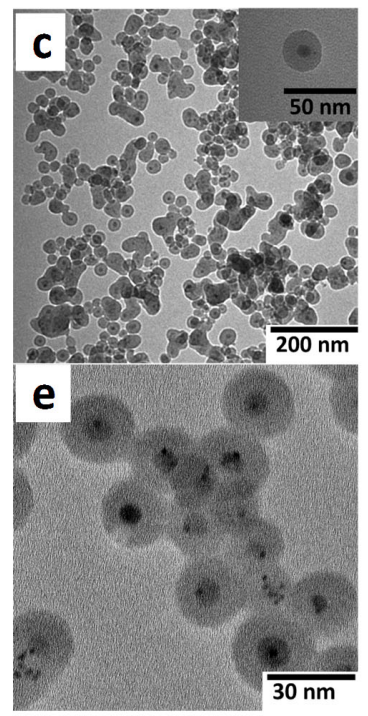
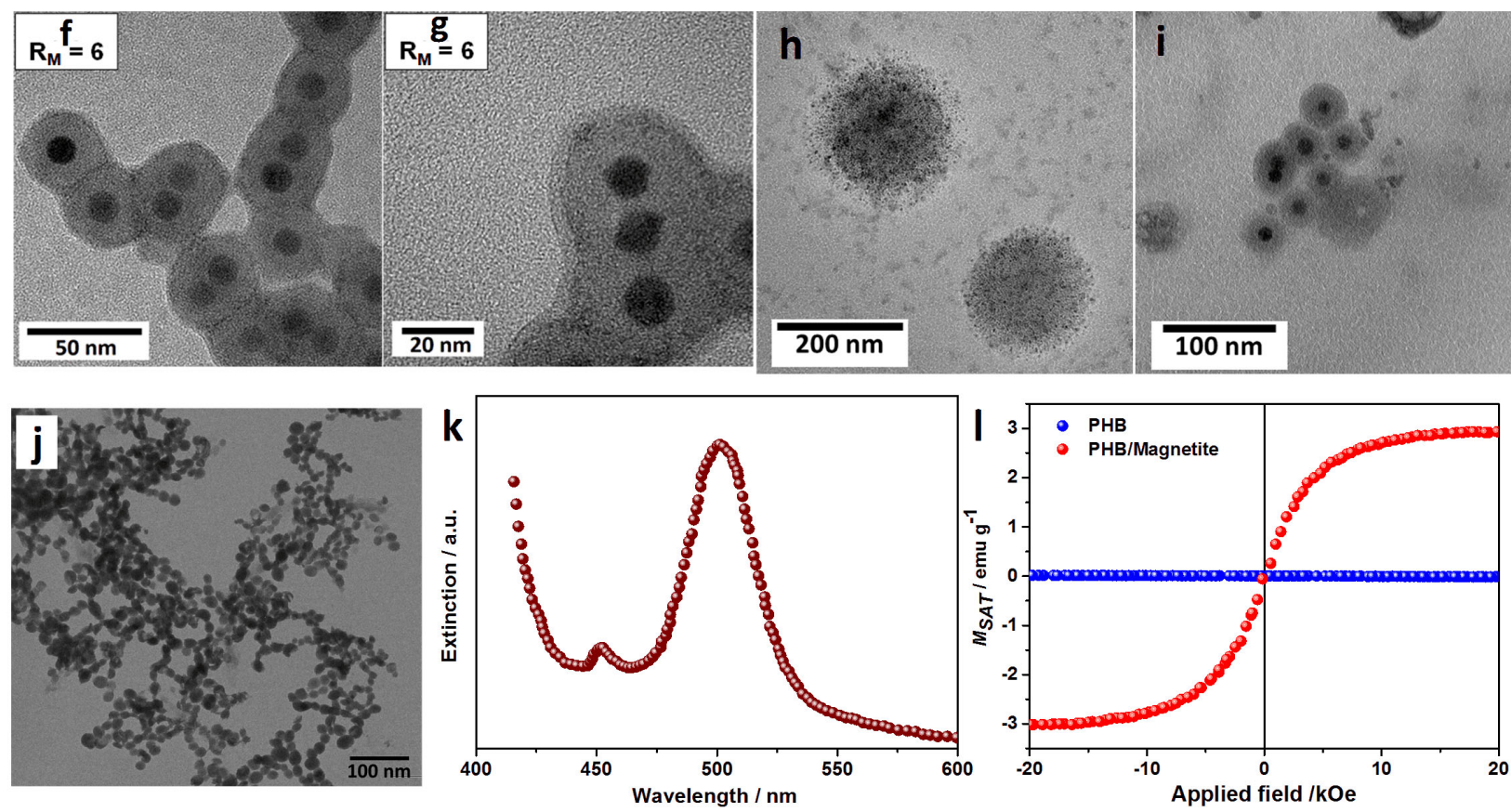

Figure 6 - (a) Typical TEM images of silica-coated magnetite nanoparticles with $5 \mathrm{~nm}, 9 \mathrm{~nm}$ and $14 \mathrm{~nm}_{\text {of }} \mathrm{SiO}_{2}$ shell thickness, (b) Schematic representation of the layer-by-layer synthesis and (c) TEM images of obtained $\mathrm{FePt}_{3} \mathrm{Fe}_{3} \mathrm{O}_{4} / \mathrm{SiO}_{2} / \mathrm{RhB}_{/} \mathrm{SiO}{ }_{2}$ luminomagnetic material. Inset in (c) showed an individual LMNP. (d) Schematic synthesis strategy and (e) TEM image of the silica-coated $\mathrm{FePt} / \mathrm{Fe}_{3} \mathrm{O}_{4}$-CdSe luminomagnetic heteronanostructure. (f) and (g) TEM images of titania-coated $\mathrm{Fe}_{3} \mathrm{O}_{4} @ \mathrm{SiO}_{2}$ magnetic nanocatalysts with $\mathrm{TiO}_{2}$ shell thickness of $2 \mathrm{~nm}$. Chitosan nanoencapsulation of magnetite nanoparticles by ionic gelification using (h) DMSA-coated magnetite and (i) hot-methanol washed nanoparticles shown individual coated-nanoparticles. (j) PHB nanoparticles scanning electron microscopy image. (k) UV-Vis spectra and (l) magnetic hysteresis loops of PHB-encapsulated CdSe and magnetite nanoparticles, respectively. 
were formed by ionic gelification method. In the case of magnetite previously washed with hot methanol to eliminate oleylamine and oleic acid molecules, assigned it a hydrophilic behavior, we can observe in Figure $6 \mathrm{i}$ that core-shell structure was obtained for individual magnetic nanoparticles. The individual nanoparticle coating was explained because DMSA coating with carboxyl and amino groups interact with chitosan and TPP ions resulting in the net of magnetic nanoparticles distributed into the chitosan matrix.

Encapsulation of the magnetic and semiconductor nanoparticles arouses much attention of the scientific community due to their promising application. In this work, for performing the CdSe and magnetite encapsulation by poly(hydroxybutyrate) (PHB), the inorganic particles were added separately, to the PHB solution at a concentration of $1 \mathrm{mg} \mathrm{mL}^{-1}$, then the encapsulation process was prepared by the solvent displacement method (Bini et al. 2016, Bini et al. 2017). Figure 6j shows the scanning electron microscopy images of the nanoparticles obtained by the solvent displacement method and, the photoluminescence spectrum and the magnetic hysteresis of the respective inorganic particles encapsulated. The photoluminescence spectrum shows two peaks around 452 and $500 \mathrm{~nm}$ (Figure 6k). The emission band centered at $500 \mathrm{~nm}$ indicates the CdSe encapsulation. However, the emission band centered at $452 \mathrm{~nm}$ may be due to free CdSe. As the medium has the surfactant in its composition, the hydrophobic quantum dots self-organized in micelles via Tween, remaining stable in aqueous solution after washing by centrifugation and shifting the maximum of the emission band. Figure 61 shows the magnetic hysteresis curves of the PHB/Magnetite sample. The PHB sample was also analyzed to show its non-magnetic character (blue line). The pure magnetic sample had a saturation magnetization of approximately $57 \mathrm{emu} \mathrm{g}^{-1}$ (not shown), whereas $2.8 \mathrm{emu} \mathrm{g}^{-1}$ was observed for the PHB/Magnetite sample. The presence of the polymer decreases the magnetic response of the samples due to their paramagnetic property; however, the superparamagnetic profile was not changed by the polymer presence. More recently, the PBH nanoparticles developed in our group was applied to obtain a dual drug release system based on soft nanocomposites of PHB-gelatine, with hydrophobic-hydrophilic drugs encapsulation (Bini et al. 2017).

Metal noble materials also are used to coating and protect magnetic nanoparticles. The propensity of metallic cobalt nanoparticles to oxidize limits their applications, but this could be overcome by producing core/shell nanostructures that have the magnetic cobalt particle as core (Carbone and Cozzoli 2010, Chaudhuri and Paria 2012). The second material for the shell must also be specially selected using characteristics like chemical stability, compatible crystallographic structure, and surface capability to link other molecules aiming colloidal stability. Therefore, gold is an excellent choice since both $\mathrm{Co}$ and $\mathrm{Au}$ could present face-centered cubic structure, gold has better stability against oxidation than cobalt, and the well-known thiol chemistry with gold could be explored to functionalize the nanostructure. Besides that, gold nanomaterials also present the LSPR that enables applications of these nanostructures as sensors (Mayer and Hafner 2011). Core/shell Co/Au nanoparticles could be label as magneto-plasmonic nanomaterials as this system can be used in both therapy and diagnosis of cancer (Lim and Majetich 2013). The core/shell Co/Au synthesized in our group have LSPR band around the therapeutic window for biomedical applications and desired superparamagnetic properties, but the colloidal stability is still an issue to be solved aiming these applications (Souza and Varanda 2018). 


\section{CURRENT CHALLENGES AND FUTURE DIRECTIONS}

In a general way, the synthesis of monodispersed nanoparticles with tunable size and shape requires tremendous efforts to adjust the reaction conditions to be reproducible. In the last decades, although the methodologies based on the modified polyol process and the thermal decomposition have shown to be capable of controlling inorganic nanocrystals morphology, the synthesis conditions are not trivial, and in almost all the cases, the success was achieved by empirical adjustments in the applied procedures. Reproducibility is always a key issue in any process. In wet-chemistry systems at high temperatures, the balance of thermodynamic and kinetic parameters becomes more delicate. The reactions in the mentioned synthesis processes in this review may to some extent be simple, but the reaction system is complex, extremely dependent on the experimental conditions, and easily affected by small changes in the synthesis parameters. The parameters dependence can be illustrated by comparing our results and many others in the literature that shows tremendous variations in the nanoparticles with small changes in methodology such as quality, concentration, and nature of the reactants, heating rates, temperature and time of growth, among others. Thus, each system requires a great deal of work in the evaluation of the synthesis variables and obtain size-tunable nanoparticles. In this review, we address a part of the vast literature on the synthesis of monodisperse nanoparticles, but there are few papers reporting studies of mechanisms of nanoparticle formation by these methodologies (Beck et al. 2011b, Park et al. 2007, Niederberger and Garnweitner 2006). The study of mechanisms of nanoparticles formation is a current challenge, and its advance will make it possible to predict the effect of small variations in the synthesis conditions on the size, shape, and composition of the nanoparticles. The improvement of characterization techniques and the possibility of studies performed in situ throughout the reaction, a more significant number of studies of nanoparticle formation mechanisms are expected. The complete knowledge of the reaction evolution, recognizing reactive species (monomers), counter-ion effects and formation of metastable and reactive byproducts (intermediates) will allow significant progress in the synthesis control (Fiévet et al. 2018, Carey et al. 2015). A second challenge directly related to the study of the mechanism of the reaction is the development of computational tools, models and simulations, that allow examining the crucial parameters that can effectively disturb the final result of the synthesis. The simplest models involving experiment planning are not robust enough to elucidate the complexity of the reactions based on both polyol process or thermal decomposition synthesis of inorganic nanocrystals with tunable size, shape, and composition (Wu et al. 2016b). An excellent review was recently published by van Embden and collaborators (van Embden et al. 2015) demonstrating how simulations and models are valuable tools in understanding and planning wet-chemical syntheses involving heating processes and elevated temperatures. Specifically, on the synthesis process via wet-chemistry, it is possible to highlight a third challenge for the development of methodologies to obtain monodisperse nanoparticle systems. A recent study compiled a series of data on the chemical synthesis via the polyol process, modified polyol process, and thermal decomposition showing that so-called moderately reactive precursors such as oleic acid, oleylamine and trioctyl phosphine have better effects on the control of nanoparticles (van Embden et al. 2015). These reactants have strong coordinating action forming complexes with the metal precursors in the reaction medium, and these complexes are, in fact, the real precursors of the formation of the nanoparticles. Thereby, a third challenge lies in the limited diversity of viable precursors for polyol process and thermal decomposition syntheses. It is necessary to extend the variety of precursors by using novel organic ligands or tailoring the existing reactants to provide 
new precursors which generate appropriate coordination complex with good dispersibility in the reaction medium with suitable chemical and thermal stability for the syntheses. As we show in this review, both methodologies of the modified polyol process and thermal decomposition allow to successfully obtain monodisperse nanoparticles of metals, metal oxides and semiconductors, but the control of the composition does yet not allow the obtaining of nanocrystals of doped materials, for example. Such a challenge can be overcome by using new precursors designed or tailored specifically for a given reaction system. Another great challenge to be mentioned is the difficulty in obtaining multicomponent systems (hybrid or composite materials) maintaining the quality of the nanoparticles in the so-called one-pot syntheses. Few works in the literature have been reporting the preparation of hybrid materials using the polyol process or the thermal decomposition in a one-pot synthesis directly. Recently, we demonstrate success in obtaining hybrid materials of reduced graphene oxide and nanoparticles (rGO/NP) through the modified polyol process in a one-pot synthesis approach (Albers et al. 2019). We show the versatility of the proposed synthesis methodology by preparation of rGO hybrid materials with monodispersed nanoparticles of Au, Ag, $\mathrm{CdSe}$, $\mathrm{FePt}$, or $\mathrm{Fe}_{3} \mathrm{O}_{4}$ through small adjustments in the experimental conditions. The sixth challenge is related to the scale-up process for mass production. Although this problem may have a more technological rather than an academic aspect, even if a robust and reproducible benchtop methodology is developed, efforts are still required to scale-up it to larger scales. Temperature gradients and formation of "hot spots" under the same conditions can occur, which is frequently avoided in the laboratory scale with a reaction vessel that uses around, for example, $25 \mathrm{ml}$ of solvent. The scheme in Figure 7 summarizes both the major features and challenges concerning the methodologies based on the polyol process and thermal decomposition.

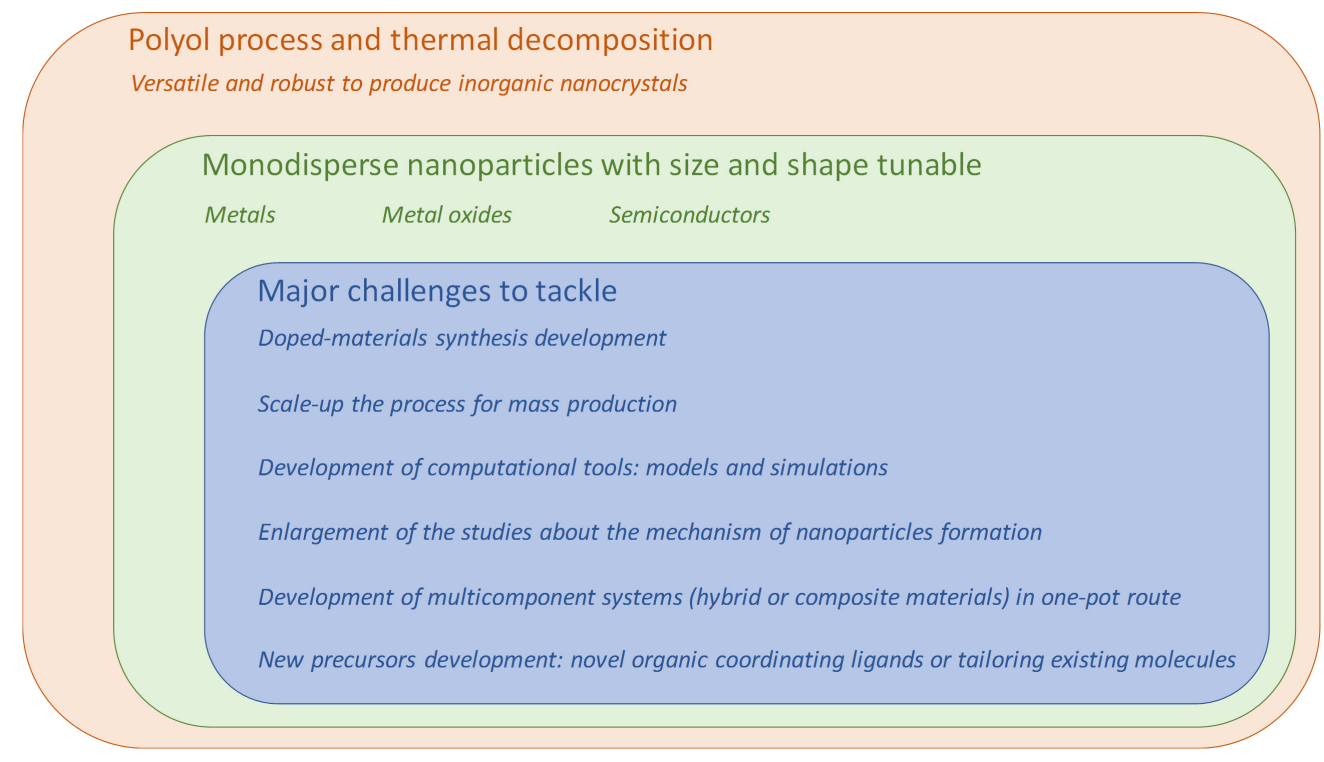

Figure 7 - The major features and challenges of the methodologies based on the polyol process and thermal decomposition.

Our results are comparable to the published data in the literature regarding the quality of the synthesized nanoparticles. We are systematically showing advances in the synthesis knowledge through mechanisms studies, the proposal of new coordinating reagents, new adjustments in the methodology, and obtaining of hybrid materials in a one-pot synthesis. We hope to continue this contribution by reinforcing the studies of 
mechanisms of the reactions that have been developed in our group and propose new routes of synthesis with tailored reactants. Besides that, we are proceeding with studies for the development of theoretical tools and simulation models to understand and control the nucleation and growth processes to obtain new inorganic nanocrystals with tunable size and shape. We hope that the materials already reported in the literature and new materials that will be obtained with the systematic advances, gradually overcoming the mentioned challenges, having many applications in several areas such as information technology, energy conversion, environment and sustainability, and biomedicine.

\section{CONCLUSIONS}

New strategies to synthesize nanoparticles and nanostructured materials are of fundamental importance for developing materials with enhanced performance. These nanomaterials have intrinsic size- and shape-dependent properties, which allow to use them as building blocks to fabricate devices for many application and using different techniques, including the self-assembled approach. Thus, new or improved synthesis methodologies by wet chemistry should enable to obtain strict control over size, shape, structure, and chemical composition, where these nanoparticle features are obtained from the adjustment of experimental parameters. In our research group, controlled size and shape nanoparticles have been synthesized mainly by modified polyol process and thermal decomposition methods, which allow obtaining wide diversity of magnetic, optical, electronic, and catalytic nanomaterials. These individual materials can be combined among themselves and subsequently functionalized lead to multifunctional nanostructured materials, that generally present water-dispersibility and low toxicity, which is required for applications in several technological areas. In the last decade, our research group has hardly worked in control over nanomaterials syntheses and in the formation mechanism comprehension by understood the nucleation and growth processes. As showed in this review, our studies allowed us to obtain different controlled materials, combine them to result in multifunctional platforms with synergic properties for catalytic, sensing, and biomedical applications.

\section{ACKNOWLEDGMENTS}

The authors gratefully acknowledge the Brazilian agencies, the Fundação de Amparo à Pesquisa do Estado de São Paulo (FAPESP) and the Conselho Nacional de Desenvolvimento Científico e Tecnológico (CNPq) for the financial supports and scholarships. Also, this study was financed in part by the Coordenação de Aperfeiçoamento de Pessoal de Nível Superior - Brazil (CAPES) - Finance Code 001.

\section{AUTHOR CONTRIBUTIONS}

All authors contributed to writing, as well as toward interpreting the results, revising, and improving the paper. The materials in this review are based on the results in our research group in the lasted years. LCV organized the paper and wrote about nucleation, growth, and challenges. DAM and JBS worked with optically active metallic and semiconductors nanomaterials; MFS, TLS, WB, and HRN worked with magnetic nanomaterials and surface engineering for magnetic recording and biomedical (theranostics) applications; CGSS work was focused on luminomagnetic (hetero)nanostructures; RAB and RFA worked, respectively, with polymeric and $\mathrm{rGO}$ /nanoparticles hybrid nanomaterials. 


\section{REFERENCES}

AKAL ZU, ALPSOY L AND BAYKAL A. 2016. Biomedical applications of SPION@APTES@PEG-folic acid@carboxylated quercetin nanodrug on various cancer cells. Appl Surf Sci 378: 572-581.

ALBERS RF, BINI RA, SOUZA JB, MACHADO DT AND VARANDA LC. 2019. A general one-pot synthetic strategy to reduced graphene oxide (rGO) and rGO-nanoparticle hybrid materials. Carbon 143: 73-84.

ALIVISATOS AP. 1996. Semiconductor clusters, nanocrystals, and quantum dots. Science 271: 933-937.

ALVAREZ PM, JARAMILLO J, LOPEZ-PINERO F AND PLUCINSKI PK. 2010. Preparation and characterization of magnetic TiO2 nanoparticles and their utilization for the degradation of emerging pollutants in water. Appl Catal B-Environ 100: 338-345.

AMENDOLA V, PILOT R, FRASCONI M, MARAGO OM AND IATI MA. 2017. Surface plasmon resonance in gold nanoparticles: a review. J Phys-Condens Mat 29: 203002.

AN K ET AL. 2006. Synthesis, characterization, and self-assembly of pencil-shaped CoO nanorods. J Am Chem Soc 128: $9753-9760$.

ARIZAGA A, MILLAN A, SCHUBERT U AND PALACIO F. 2013. Synthesis of silica-coated aqueous ferrofluids through ligand exchange with a new organosilica precursor. J Mater Sci 48: 2550-2556.

AZIZ AA, PUMA GL, IBRAHIM S AND SARAVANAN P. 2013. Preparation, characterisation and solar photoactivity of titania supported strontium ferrite nanocomposite photocatalyst. J Exp Nanosci 8: 295-310.

BAEK MJ ET AL. 2010. Water-Soluble MnO Nanocolloid for a Molecular T-1 MR Imaging: A Facile One-Pot Synthesis, In vivo T-1 MR Images, and Account for Relaxivities. Acs Appl Mater Inter 2: 2949-2955.

BARONOV A, BUFKIN K, SHAW DW, JOHNSON BL AND PATRICK DL. 2015. A simple model of burst nucleation. Phys Chem Chem Phys 17: 20846-20852.

BECK W, JAFEFICCI M AND VARANDA LC. 2011a. Magnetic and Multifunctional Magnetic Nanoparticles in Nanomedicine: Challenges and Trends in Synthesis and Surface Engineering for Diagnostic and Therapy Applications. In: Laskovski AN (Ed), Biomedical Engineering: Trends in materials science, Rijeka, Croatia: Intech, p. 397-424.

BECK W, SOUZA CGS, SILVA TL, JAFELICCI M AND VARANDA LC. 2011b. Formation mechanism via a heterocoagulation approach of FePt nanoparticles using the modified polyol process. J Phys Chem C 115: 10475-10482.

BERNKOP-SCHNURCH A AND DUNNHAUPT S. 2012. Chitosan-based drug delivery systems. Eur J Pharm Biopharm 81: 463-469.

BINI RA, MORAES DA AND VARANDA LC. 2016. Preparation of Poly(3-hydroxybutyrate) Micro- and Nanoparticles as Hydrophobic Drugs Carrier Using Self-emulsifying Nanoemulsion Method. Brit J Pharm Res 12: 28070.

BINI RA, SILVA MF, VARANDA LC, DA SILVA MA AND DREISS CA. 2017. Soft nanocomposites of gelatin and poly(3-hydroxybutyrate) nanoparticles for dual drug release. Colloid Surface B 157: 191-198.

BLOEMEN M, BRULLOT W, LUONG TT, GEUKENS N, GILS A AND VERBIEST T. 2012. Improved functionalization of oleic acid-coated iron oxide nanoparticles for biomedical applications. J Nanopart Res 14: 1100.

BOLES MA, ENGEL M AND TALAPIN DV. 2016. Self-Assembly of Colloidal Nanocrystals: From Intricate Structures to Functional Materials. Chem Rev 116: 11220-11289.

BORRONI E ET AL. 2017. Tumor targeting by lentiviral vectors combined with magnetic nanoparticles in mice. Acta Biomater 59: 303-316.

BOTT-NETO JL, BECK W, VARANDA LC AND TICIANELLI EA. 2017. Electrocatalytic activity of platinum nanoparticles supported on different phases of tungsten carbides for the oxygen reduction reaction. Int J Hydrogen Energy 42: 20677-20688.

BURDA C, CHEN XB, NARAYANAN R AND EL-SAYED MA. 2005. Chemistry and properties of nanocrystals of different shapes. Chem Rev 105: 1025-1102.

CALVO P, REMUNANLOPEZ C, VILAJATO JL AND ALONSO MJ. 1997. Novel hydrophilic chitosan-polyethylene oxide nanoparticles as protein carriers. J Appl Polym Sci 63: 125-132.

CARBONE L AND COZZOLI PD. 2010. Colloidal heterostructured nanocrystals: Synthesis and growth mechanisms. Nano Today 5: 449-493.

CAREY JL, WHITCOMB DR, CHEN S, PENN RL AND BÜHLMANN P. 2015. Potentiometric in Situ Monitoring of Anions in the Synthesis of Copper and Silver Nanoparticles Using the Polyol Process. ACS Nano 9: 12104-12114.

CAVICCHIOLI M, VARANDA LC, MASSABNI AC AND MELNIKOV P. 2005. Silver nanoparticles synthesized by thermal reduction of a silver(I)-aspartame complex in inert atmosphere. Mater Lett 59: 3585-3589.

CHAUDHURI RG AND PARIA S. 2012. Core/Shell Nanoparticles: Classes, Properties, Synthesis Mechanisms, Characterization, and Applications. Chem Rev 112: 2373-2433.

CHEN JY, QIAN YX AND WEI XZ. 2010. Comparison of magnetic-nanometer titanium dioxide/ferriferous oxide $\left(\mathrm{TiO}_{2} / \mathrm{Fe}_{3} \mathrm{O}_{4}\right)$ composite photocatalyst prepared by acid-sol and homogeneous precipitation methods. J Mater Sci 45: 6018-6024. 
CHEN K, SONG S, LIU F AND XUE D. 2015. Structural design of graphene for use in electrochemical energy storage devices. Chem Soc Rev 44: 6230-6257.

CHEN M, KIM J, LIU JP, FAN HY AND SUN SH. 2006. Synthesis of FePt nanocubes and their oriented self-assembly. J Am Chem Soc 128: 7132-7133.

CORR SA, RAKOVICH YP AND GUN'KO YK. 2008. Multifunctional magnetic-fluorescent nanocomposites for biomedical applications. Nanoscale Res Lett 3: 87-104.

COSTI R, SAUNDERS AE AND BANIN U. 2010. Colloidal Hybrid Nanostructures: A New Type of Functional Materials. Angew Chem Int Edit 49: 4878-4897.

COZZOLI PD, PELLEGRINO T AND MANNA L. 2006. Synthesis, properties and perspectives of hybrid nanocrystal structures. Chem Soc Rev 35: 1195-1208.

CRETI A, ANNI M, ZAVELANI-ROSSI M, LANZANI G, LEO G, DELLA SALA F, MANNA L AND LOMASCOLO M. 2005. Ultrafast carrier dynamics in core and core/shell CdSe quantum rods: Role of the surface and interface defects. Phys Rev B 72 : 125346.

DABBOUSI BO, RODRIGUEZVIEJO J, MIKULEC FV, HEINE JR, MATTOUSSI H, OBER R, JENSEN KF AND BAWENDI MG. 1997. (CdSe)ZnS core-shell quantum dots: Synthesis and characterization of a size series of highly luminescent nanocrystallites. J Phys Chem B 101: 9463-9475.

DAMATO TC, DE OLIVEIRA CCS, ANDO RA AND CAMARGO PHC. 2013. A Facile Approach to TiO $\mathrm{C}_{2}$ Colloidal Spheres Decorated with Au Nanoparticles Displaying Well-Defined Sizes and Uniform Dispersion. Langmuir 29: 1642-1649.

DASGUPTA N, RANJAN S, MUNDEKKAD D, RAMALINGAM C, SHANKER R AND KUMAR A. 2015. Nanotechnology in agro-food: From field to plate. Food Res Int 69: 381-400.

DA SILVA TL AND VARANDA LC. 2011. Perpendicularly self-oriented and shape-controlled $\mathrm{L}_{10}$-FePt nanorods directly synthesized by a temperature-modulated process. Nano Res 4: 666-674.

DEHGHANI F, SARDARIAN AR AND ESMAEILPOUR M. 2013. Salen complex of Cu(II) supported on superparamagnetic $\mathrm{Fe}_{3} \mathrm{O}_{4} @ \mathrm{SiO}_{2}$ nanoparticles: An efficient and recyclable catalyst for synthesis of 1-and 5-substituted 1H-tetrazoles. J Organomet Chem 743: 87-96.

DENG YH, WANG CC, HU JH, YANG WL AND FU SK. 2005. Investigation of formation of silica-coated magnetite nanoparticles via sol-gel approach. Colloid Surface A 262: 87-93.

DIAS MHM AND LAUTERBUR PC. 1986. Ferromagnetic Particles as Contrast Agents for Magnetic-Resonance-Imaging of Liver and Spleen. Magnet Reson Med 3: 328-330.

DING HL, ZHANG YX, WANG S, XU JM, XU SC AND LI GH. 2012. Fe $\mathrm{O}_{4} @ \mathrm{SiO}_{2}$ Core/Shell Nanoparticles: The Silica Coating Regulations with a Single Core for Different Core Sizes and Shell Thicknesses. Chem Mater 24: 4572-4580.

DONEGA CD, LILJEROTH P AND VANMAEKELBERGH D. 2005. Physicochemical evaluation of the hot-injection method, a synthesis route for monodisperse nanocrystals. Small 1: 1152-1162.

FAN W, YAN W, XU ZS AND NI H. 2012. Formation mechanism of monodisperse, low molecular weight chitosan nanoparticles by ionic gelation technique. Colloid Surface B 90: 21-27.

FARADAY M. 1857. The Bakerian Lecture: Experimental Relations of Gold (and Other Metals) to Light. Philos Trans R Soc London, Ser A 147: 145-181.

FENG L AND LIU Z. 2011. Graphene in biomedicine: opportunities and challenges. Nanomedicine 6: 317-324.

FIEVET F, LAGIER JP, BLIN B, BEAUDOIN B AND FIGLARZ M. 1989. Homogeneous and Heterogeneous Nucleations in the Polyol Process for the Preparation of Micron and Sub-Micron Size Metal Particles. Solid State Ionics 32-3: 198-205.

FIÉVET F, AMMAR-MERAH AS, BRAYNER AR, CHAU AF, GIRAUD AM, MAMMERI AF, PERON AJ, PIQUEMAL AJY, SICARDA AL AND VIAUB G. 2018. The polyol process: a unique method for easy access to metal nanoparticles with tailored sizes, shapes and compositions. Chem Soc Rev 47: 5187-5233.

FINNEY EE AND FINKE RG. 2008a. The four-step, double-autocatalytic mechanism for transition-metal nanocluster nucleation, growth, and then agglomeration: Metal, ligand, concentration, temperature, and solvent dependency studies. Chem Mater 20: 1956-1970.

FINNEY EE AND FINKE RG. 2008b. Nanocluster nucleation and growth kinetic and mechanistic studies: A review emphasizing transition-metal nanoclusters. J Colloid Interface Sci 317: 351-374.

FREESTONE I, MEEKS N, SAX M AND HIGGITT C. 2007. The Lycurgus Cup - A Roman nanotechnology. Gold Bull 40: 270-277.

FU WY, YANG HB, LI MH, LI MH, YANG N AND ZOU GT. 2005. Anatase $\mathrm{TiO}_{2}$ nanolayer coating on cobalt ferrite nanoparticles for magnetic photocatalyst. Mater Lett 59: 3530-3534.

GARCIA-GARRIDO SE, FRANCOS J, CADIERNO V, BASSET JM AND POLSHETTIWAR V. 2011. Chemistry by 
Nanocatalysis: First Example of a Solid-Supported RAPTA Complex for Organic Reactions in Aqueous Medium. Chemsuschem 4: 104-111.

GHOSH M, SAMPATHKUMARAN EV AND RAO CNR. 2005. Synthesis and magnetic properties of CoO nanoparticles. Chem Mater 17: 2348-2352.

GOMEZ-MARIN AM, BOTT-NETO JL, SOUZA JB, SILVA TL, BECK W, VARANDA LC AND TICIANELLI EA. 2016. Electrocatalytic Activity of Different Phases of Molybdenum Carbide/Carbon and Platinum-Molybdenum Carbide/Carbon Composites toward the Oxygen Reduction Reaction. Chemelectrochem 3: 1570-1579.

GONZALEZ-GARCIA L, MAURER JHM, REISER B, KANELIDIS I AND KRAUS T. 2016. Ultrathin gold nanowires for transparent electronics: breaking barriers. Procedia Engineer 141: 152-156.

GUO B, YIM H, KHASANOV A AND STEVENS J. 2010. Formation of Magnetic $\mathrm{Fe}_{\mathrm{x}} \mathrm{O}_{\mathrm{y}} /$ Silica Core-Shell Particles in a One-Step Flame Aerosol Process. Aerosol Sci Technol 44: 281-291.

GUO SJ, LI DG, ZHU HY, ZHANG S, MARKOVIC NM, STAMENKOVIC VR AND SUN SH. 2013. FePt and CoPt Nanowires as Efficient Catalysts for the Oxygen Reduction Reaction. Angew Chem Int Edit 52: 3465-3468.

GUPTA AK AND GUPTA M. 2005. Synthesis and surface engineering of iron oxide nanoparticles for biomedical applications. Biomaterials 26: 3995-4021.

HAO R, XING RJ, XU ZC, HOU YL, GAO S AND SUN SH. 2010. Synthesis, Functionalization, and Biomedical Applications of Multifunctional Magnetic Nanoparticles. Adv Mater 22: 2729-2742.

HARRA J, NIKKANEN JP, AROMAA M, SUHONEN H, HONKANEN M, SALMINEN T, HEINONEN S, LEVANEN E AND MAKELA JM. 2013. Gas phase synthesis of encapsulated iron oxide-titanium dioxide composite nanoparticles by spray pyrolysis. Powder Technol 243: 46-52.

HIRAMATSU H AND OSTERLOH FE. 2004. A simple large-scale synthesis of nearly monodisperse gold and silver nanoparticles with adjustable sizes and with exchangeable surfactants. Chem Mater 16: 2509-2511.

HSU BYW, KIRBY G, TAN A, SEIFALIAN AM, LI X AND WANG J. 2016. Relaxivity and toxicological properties of manganese oxide nanoparticles for MRI applications. RSC Adv 6: 45462-45474.

HUANG M, LI F, DONG F, ZHANG YX AND ZHANG LL. 2015. $\mathrm{MnO}_{2}$-based nanostructures for high-performance supercapacitors. J Mater Chem A 3: 21380-21423.

HUI C, SHEN CM, TIAN JF, BAO LH, DING H, LI C, TIAN YA, SHI XZ AND GAO HJ. 2011. Core-shell Fe $\mathrm{O}_{4} @ \mathrm{SiO}_{2}$ nanoparticles synthesized with well-dispersed hydrophilic $\mathrm{Fe}_{3} \mathrm{O}_{4}$ seeds. Nanoscale 3: 701-705.

HUNTER RJ. 2001. Foundations of Colloid Science. $2^{\text {nd }}$ ed, New York: Oxford University Press Inc., 816 p.

IQBAL MZ, MA XH, CHEN TX, ZHANG LE, REN WZ, XIANG LC AND WU AG. 2015. Silica-coated super-paramagnetic iron oxide nanoparticles (SPIONPs): a new type contrast agent of T-1 magnetic resonance imaging (MRI). J Mater Chem B 3 : 5172-5181.

JANZEN C, KNIPPING J, RELLINGHAUS B AND ROTH P. 2003. Formation of silica-embedded iron-oxide nanoparticles in low-pressure flames. J Nanopart Res 5: 589-596.

JOHN R ET AL. 2017. Magnetisation switching of FePt nanoparticle recording medium by femtosecond laser pulses. Sci Rep 7: 4114.

KELLY KL, CORONADO E, ZHAO LL AND SCHATZ GC. 2003. The optical properties of metal nanoparticles: The influence of size, shape, and dielectric environment. J Phys Chem B 107: 668-677.

KHALKHALI M, ROSTAMIZADEH K, SADIGHIAN S, KHOEINI F, NAGHIBI M AND HAMIDI M. 2015. The impact of polymer coatings on magnetite nanoparticles performance as MRI contrast agents: a comparative study. DARU J Pharm Sci 23 : 45.

KHAN MA, AL-OUFI M, TOSSEF A, AL-SALIK Y AND IDRISS H. 2015. On the role of $\mathrm{CoO}$ in $\mathrm{CoO}_{\mathrm{x}} / \mathrm{TiO}_{2}$ for the photocatalytic hydrogen production from water in the presence of glycerol. Catal Struct React 1: 192-200.

KIM DW, KIM TH, CHOI S, KIM KS AND PARK DW. 2012. Preparation of silica coated iron oxide nanoparticles using non-transferred arc plasma. Adv Powder Technol 23: 701-707.

KIMLING J, MAIER M, OKENVE B, KOTAIDIS V, BALLOT H AND PLECH A. 2006. Turkevich method for gold nanoparticle synthesis revisited. J Phys Chem B 110: 15700-15707.

KOVALENKO MV ET AL. 2015. Prospects of Nanoscience with Nanocrystals. ACS Nano 9: 1012-1057.

KWON SG AND HYEON T. 2008. Colloidal Chemical Synthesis and Formation Kinetics of Uniformly Sized Nanocrystals of Metals, Oxides, and Chalcogenides. Acc Chem Res 41: 1696-1709.

KWON SG AND HYEON T. 2011. Formation Mechanisms of Uniform Nanocrystals via Hot-Injection and Heat-Up Methods. Small 7: 2685-2702.

LAMER VK. 1952. Nucleation in Phase Transitions. Ind Eng Chem 44: 1270-1277. 
LAMER VK AND DINEGAR RH. 1950. Theory, Production and Mechanism of Formation of Monodispersed Hydrosols. J Am Chem Soc 72: 4847-4854.

LEE GH, HUH SH, JEONG JW, CHOI BJ, KIM SH AND RI HC. 2002. Anomalous magnetic properties of MnO nanoclusters. J Am Chem Soc 124: 12094-12095.

LEE JH ET AL. 2007. Artificially engineered magnetic nanoparticles for ultra-sensitive molecular imaging. Nat Med 13: 95-99.

LEE SW, DRWIEGA J, MAZYCK D, WU CY AND SIGMUND WM. 2006. Synthesis and characterization of hard magnetic composite photocatalyst - Barium ferrite/silica/titania. Mater Chem Phys 96: 483-488.

LIA JJ AND ZHU JJ. 2013. Quantum dots for fluorescent biosensing and bio-imaging applications. Analyst 138: $2506-2515$.

LIM J AND MAJETICH SA. 2013. Composite magnetic-plasmonic nanoparticles for biomedicine: Manipulation and imaging. Nano Today 8: 98-113.

LIMA JRD, GHANI YA, DA SILVA RB, BATISTA FMC, BINI RA, VARANDA LC AND DE OLIVEIRA JE. 2012. Strontium zirconate heterogeneous catalyst for biodiesel production: Synthesis, characterization and catalytic activity evaluation. Appl Catal A 445: 76-82.

LI Q, KARTIKOWATI CW, HORIE S, OGI T, IWAKI T AND OKUYAMA K. 2017. Correlation between particle size/domain structure and magnetic properties of highly crystalline $\mathrm{Fe}_{3} \mathrm{O}_{4}$ nanoparticles. Sci Rep 7: 9894.

LIU S, CHEN GY, PRASAD PN AND SWIHART MT. 2011. Synthesis of Monodisperse Au, Ag, and Au-Ag Alloy Nanoparticles with Tunable Size and Surface Plasmon Resonance Frequency. Chem Mater 23: 4098-4101.

LU AH, SALABAS EL AND SCHUTH F. 2007. Magnetic nanoparticles: Synthesis, protection, functionalization, and application. Angew Chem Int Edit 46: 1222-1244.

LU AL, CHEN YZ, ZENG DQ, LI M, XIE QS, ZHANG XX AND PENG DL. 2014. Shape-related optical and catalytic properties of wurtzite-type $\mathrm{CoO}$ nanoplates and nanorods. Nanotechnology 25: 035707.

LU Y, YIN YD, MAYERS BT AND XIA YN. 2002. Modifying the surface properties of superparamagnetic iron oxide nanoparticles through a sol-gel approach. Nano Lett 2: 183-186.

MARQUES RFC, JAFELICCI M, PAIVA-SANTOS CO, VARANDA LC AND GODOI RHM. 2001. In situ solid state oxidation reaction for $\mathrm{La}_{1-\mathrm{x}} \mathrm{Sr}_{\mathrm{x}} \mathrm{MnO}_{3}(\mathrm{x}=0,0.1,0.2$ and 0.3) formation. J Magn Magn Mater 226: 812-814.

MARTIN MN, BASHAM JI, CHANDO P AND EAH SK. 2010. Charged Gold Nanoparticles in Non-Polar Solvents: 10-min Synthesis and 2D Self-Assembly. Langmuir 26: 7410-7417.

MASARUDIN MJ, CUTTS SM, EVISON BJ, PHILLIPS DR AND PIGRAM PJ. 2015. Factors determining the stability, size distribution, and cellular accumulation of small, monodisperse chitosan nanoparticles as candidate vectors for anticancer drug delivery: application to the passive encapsulation of [C-14]-doxorubicin. Nanotechnol Sci Appl 8: 67-80.

MAURER JHM, GONZALEZ-GARCIA L, REISER B, KANELIDIS I AND KRAUS T. 2015. Sintering of Ultrathin Gold Nanowires for Transparent Electronics. Acs Appl Mater Inter 7: 7838-7842.

MAURER JHM, GONZALEZ-GARCIA L, REISER B, KANELIDIS I AND KRAUS T. 2016. Templated Self-Assembly of Ultrathin Gold Nanowires by Nanoimprinting for Transparent Flexible Electronics. Nano Lett 16: 2921-2925.

MAYER KM AND HAFNER JH. 2011. Localized Surface Plasmon Resonance Sensors. Chem Rev 111: 3828-3857.

MAZZU-NASCIMENTO T, DONOFRIO FC, BIANCHI BC, TRAVENSOLO RD, SOUZA JB, MORAES DA, MORBIOLI GG, SEGATO TP, VARANDA LC AND CARRILHO E. 2017. Paper-Based Microfluidics Immunoassay for Detection of Canine Distemper Virus. Braz Arch Biol Techn 60: e17160317.

MOREL AL ET AL. 2008. Sonochemical approach to the synthesis of $\mathrm{Fe}_{3} \mathrm{O}_{4} @ \mathrm{SiO}_{2}$ core-shell nanoparticles with tunable properties. ACS Nano 2: 847-856.

MULLIN JW. 2001. Crystallization. 4th ed, Boston, USA: Butterworth-Heinemann, 594 p.

MURRAY CB, NORRIS DJ AND BAWENDI MG. 1993. Synthesis and Characterization of Nearly Monodisperse CdE (E = S, Se, Te) Semiconductor Nanocrystallites. J Am Chem Soc 115: 8706-8715.

MURRAY CB, SUN SH, DOYLE H AND BETLEY T. 2001. Monodisperse 3d transition-metal (Co, Ni, Fe) nanoparticles and their assembly into nanoparticle superlattices. MRS Bull 26: 985-991.

NA HB ET AL. 2007. Development of a T-1 contrast agent for magnetic resonance imaging using MnO nanoparticles. Angew Chem Int Edit 46: 5397-5401.

NAIR RV, SANTHAKUMAR H AND JAYASREE RS. 2018. Gold nanorods decorated with a cancer drug for multimodal imaging and therapy. Faraday Discuss 207: 423-435.

NEVES HR, BINI RA, BARBOSA JHO, SALMON CEG AND VARANDA LC. 2016. Dextran-Coated Antiferromagnetic MnO Nanoparticles for a T-1-MRI Contrast Agent with High Colloidal Stability. Part Part Syst Charact 33: 167-176.

NGUYEN TD. 2013. From formation mechanisms to synthetic methods toward shape-controlled oxide nanoparticles. Nanoscale 5: 9455-9482. 
NIEDERBERGER M AND GARNWEITNER, G. 2006. Organic Reaction Pathways in the Nonaqueous Synthesis of Metal Oxide Nanoparticles, Chem Eur J 12: 7282-7302.

NORRIS DJ AND BAWENDI MG. 1996. Measurement and assignment of the size-dependent optical spectrum in CdSe quantum dots. Phys Rev B 53: 16338-16346.

OCHIAI T AND FUJISHIMA A. 2012. Photoelectrochemical properties of $\mathrm{TiO}_{2}$ photocatalyst and its applications for environmental purification. J Photoch Photobio C 13: 247-262.

OHKOSHI S ET AL. 2016. Multimetal-Substituted Epsilon-Iron Oxide epsilon- $\mathrm{Ga}_{0.31} \mathrm{Ti}_{0.05} \mathrm{Co}_{0.05} \mathrm{Fe}_{1.59} \mathrm{O}_{3}$ for Next-Generation Magnetic Recording Tape in the Big-Data Era. Angew Chem Int Edit 55: 11403-11406.

OSTWALD W. 1900. On the assumed isomerism of red and yellow mercury oxide and the surface-tension of solid bodies. Z Phys Chem-Stoch Ve 34: 495-503.

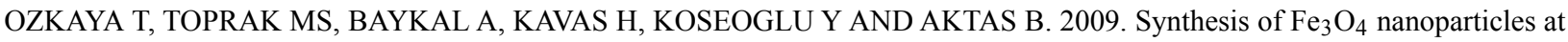
100 degrees $C$ and its magnetic characterization. J Alloys Compd 472: 18-23.

PANG HA, LI YC, GUAN LN, LU QY AND GAO F. 2011. $\mathrm{TiO}_{2} / \mathrm{Ni}$ nanocomposites: Biocompatible and recyclable magnetic photocatalysts. Catal Commun 12: 611-615.

PARK J, AN KJ, HWANG YS, PARK JG, NOH HJ, KIM JY, PARK JH, HWANG NM AND HYEON T. 2004. Ultra-large-scale syntheses of monodisperse nanocrystals. Nat Mater 3: 891-895.

PARK J, JOO J, KWON SG, JANG Y AND HYEON T. 2007. Synthesis of monodisperse spherical nanocrystals. Angew Chem Int Edit 46: 4630-4660.

PENG XG, WICKHAM J AND ALIVISATOS AP. 1998. Kinetics of II-VI and III-V colloidal semiconductor nanocrystal growth: "Focusing" of size distributions. J Am Chem Soc 120: 5343-5344.

PIETRYGA JM, PARK YS, LIM JH, FIDLER AF, BAE WK, BROVELLI S AND KLIMOV VI. 2016. Spectroscopic and Device Aspects of Nanocrystal Quantum Dots. Chem Rev 116: 10513-10622.

PUNTES VF, KRISHNAN KM AND ALIVISATOS AP. 2001. Colloidal nanocrystal shape and size control: The case of cobalt. Science 291: 2115-2117.

QI QQ, CHEN YZ, WANG LS, ZENG DQ AND PENG DL. 2016. Phase-controlled synthesis and magnetic properties of cubic and hexagonal CoO nanocrystals. Nanotechnology 27: 455602.

QU LH, PENG ZA AND PENG XG. 2001. Alternative routes toward high quality CdSe nanocrystals. Nano Lett 1: 333-337.

RAUTA PR, HALLUR PM AND CHAUBEY A. 2018. Gold nanoparticle-based rapid detection and isolation of cells using ligand-receptor chemistry. Sci Rep 8: 2893.

REISS H. 1951. The Growth of Uniform Colloidal Dispersions. J Chem Phys 19: 482-487.

ROGACH AL, TALAPIN DV, SHEVCHENKO EV, KORNOWSKI A, HAASE M AND WELLER H. 2002. Organization of matter on different size scales: Monodisperse nanocrystals and their superstructures. Adv Funct Mater 12: 653-664.

SANTIAGO EI, VARANDA LC AND VILLULLAS HM. 2007. Carbon-supported Pt-Co catalysts prepared by a modified polyol process as cathodes for PEM fuel cells. J Phys Chem C 111: 3146-3151.

SANTOS FJ, VARANDA LC, FERRACIN LC AND JAFELICCI M. 2008. Synthesis and electrochemical behavior of single-crystal magnetite nanoparticles. J Phys Chem C 112: 5301-5306.

SANTRA S, TAPEC R, THEODOROPOULOU N, DOBSON J, HEBARD A AND TAN WH. 2001. Synthesis and characterization of silica-coated iron oxide nanoparticles in microemulsion: The effect of nonionic surfactants. Langmuir 17: $2900-2906$.

SCHLADT TD ET AL. 2012. Multifunctional superparamagnetic $\mathrm{MnO} @ \mathrm{SiO}_{2}$ core/shell nanoparticles and their application for optical and magnetic resonance imaging. J Mater Chem 22: 9253-9262.

SEO WS, SHIM JH, OH SJ, LEE EK, HUR NH AND PARK JT. 2005. Phase- and size-controlled synthesis of hexagonal and cubic CoO nanocrystals. J Am Chem Soc 127: 6188-6189.

SETYAWAN H, FAJAROH F, WIDIYASTUTI W, WINARDI S, LENGGORO IW AND MUFTI N. 2012. One-step synthesis of silica-coated magnetite nanoparticles by electrooxidation of iron in sodium silicate solution. J Nanopart Res 14: 807.

SODIPO BK AND AZIZ AA. 2015. Non-seeded synthesis and characterization of superparamagnetic iron oxide nanoparticles incorporated into silica nanoparticles via ultrasound. Ultrason Sonochem 23: 354-359.

SODIPO BK AND AZIZ AA. 2016. Recent advances in synthesis and surface modification of superparamagnetic iron oxide nanoparticles with silica. J Magn Magn Mater 416: 275-291.

SONG Q, DING Y, WANG ZL AND ZHANG ZJ. 2007. Tuning the thermal stability of molecular precursors for the nonhydrolytic synthesis of magnetic $\mathrm{MnFe}_{2} \mathrm{O}_{4}$ spinel nanocrystals. Chem Mater 19: 4633-4638.

SOUZA CGS, BECK W AND VARANDA LC. 2013. Multifunctional luminomagnetic $\mathrm{FePt} @ \mathrm{Fe}_{3} \mathrm{O}_{4} / \mathrm{SiO}_{2} / \mathrm{Rhodamine} \mathrm{B} / \mathrm{SiO}_{2}$ nanoparticles with high magnetic emanation for biomedical applications. J Nanopart Res 15: 1545.

SOUZA CGS, SOUZA JB, BECK W AND VARANDA LC. 2017. Luminomagnetic Silica-Coated Heterodimers of Core/Shell 
FePt/Fe3O4 and CdSe Quantum Dots as Potential Biomedical Sensor. J Nanomater 2017: 2160278.

SOUZA JB AND VARANDA LC. 2018. Magneto-plasmonic Au-Coated Co nanoparticles synthesized via hot-injection method. Nanotechnology 29: 065604.

SOZER N AND KOKINI JL. 2009. Nanotechnology and its applications in the food sector. Trends Biotechnol $27: 82-89$.

SU JW, ZHANG YX, XU SC, WANG S, DING HL, PAN SS, WANG GZ, LI GH AND ZHAO HJ. 2014. Highly efficient and recyclable triple-shelled $\mathrm{Ag} @ \mathrm{Fe}_{3} \mathrm{O}_{4} @ \mathrm{SiO}_{2} @ \mathrm{TiO}_{2}$ photocatalysts for degradation of organic pollutants and reduction of hexavalent chromium ions. Nanoscale 6: 5181-5192.

SUGIMOTO T. 2001. Monodispersed Particles. Amsterdam: Elsevier.

SUN SH, FULLERTON EE, WELLER D AND MURRAY CB. 2001. Compositionally controlled FePt nanoparticle materials. Ieee T Magn 37: 1239-1243.

SUN S, MURRAY CB, WELLER D, FOLKS L AND MOSER A. 2000. Monodisperse FePt Nanoparticles and Ferromagnetic FePt Nanocrystal Superlattices. Science 287: 1989.

TAKAHATA R, YAMAZOE S, KOYASU K AND TSUKUDA T. 2014. Surface Plasmon Resonance in Gold Ultrathin Nanorods and Nanowires. J Am Chem Soc 136: 8489-8491.

TALAPIN DV, ROGACH AL, HAASE M AND WELLER H. 2001. Evolution of an ensemble of nanoparticles in a colloidal solution: Theoretical study. J Phys Chem B 105: 12278-12285.

TARTAJ P, MORALES MD, VEINTEMILLAS-VERDAGUER S, GONZALEZ-CARRENO T AND SERNA CJ. 2003. The preparation of magnetic nanoparticles for applications in biomedicine. J Phys D: Appl Phys 36: R182-R197.

TAWKAEW S AND SUPOTHINA S. 2008. Preparation of agglomerated particles of $\mathrm{TiO}_{2}$ and silica-coated magnetic particle. Mater Chem Phys 108: 147-153.

TELEKI A, SUTER M, KIDAMBI PR, ERGENEMAN O, KRUMEICH F, NELSON BJ AND PRATSINIS SE. 2009. Hermetically Coated Superparamagnetic $\mathrm{Fe}_{2} \mathrm{O}_{3}$ Particles with $\mathrm{SiO}_{2}$ Nanofilms. Chem Mater 21: 2094-2100.

THANH NTK, MACLEAN N AND MAHIDDINE S. 2014. Mechanisms of Nucleation and Growth of Nanoparticles in Solution. Chem Rev 114: 7610-7630.

VALLABANI NVS AND SINGH S. 2018. Recent advances and future prospects of iron oxide nanoparticles in biomedicine and diagnostics. 3 Biotech 8: 279.

VAN EMBDEN J, CHESMAN ASR AND JASIENIAK JJ. 2015. The Heat-Up Synthesis of Colloidal Nanocrystals. Chem Mater 27: 2246-2285.

VARANDA LC, GOYA GF, MORALES MP, MARQUES RFC, GODOI RHM, JAFELICCI M AND SERNA CJ. 2002a. Magnetic properties of acicular ultrafine iron particles. IEEE Trans Magn 38: 1907-1909.

VARANDA LC, IMAIZUMI M, SANTOS FJ AND JAFELICCI M. 2008. Iron Oxide Versus $\mathrm{Fe}_{55} \mathrm{Pt}_{45} / \mathrm{Fe}_{3} \mathrm{O}_{4}$ : Improved Magnetic Properties of Core/Shell Nanoparticles for Biomedical Applications. IEEE Trans Magn 44: 4448-4451.

VARANDA LC AND JAFELICCI M. 2006. Self-assembled FePt nanocrystals with large coercivity: reduction of the fcc-to- $\mathrm{L}_{10}$ Ordering Temperature. J Am Chem Soc 128: 11062-11066.

VARANDA LC, JAFELICCI M AND GOYA GF. 2001. Magnetic properties of spindle-type iron fine particles obtained from hematite. J Magn Magn Mater 226: 1933-1935.

VARANDA LC, JAFELICCI M AND IMAIZUMI M. 2007. Temperature dependence and magnetocrystalline anisotropy studies of self-assembled $\mathrm{L} 1_{0}-\mathrm{Fe}_{55} \mathrm{Pt}_{45}$ ferromagnetic nanocrystals. J Appl Phys 101: 123918.

VARANDA LC, JAFELICCI M, TARTAJ P, O' GRADY K, GONZALEZ-CARRENO T, MORALES MP, MUNOZ T AND SERNA CJ. 2002b. Structural and magnetic transformation of monodispersed iron oxide particles in a reducing atmosphere. J Appl Phys 92: 2079-2085.

VARANDA LC, MORALES MP, GOYA GF, IMAIZUMI M, SERNA CJ AND JAFELICCI M. 2004. Magnetic properties of acicular $\mathrm{Fe}_{1-\mathrm{x}} \mathrm{RE}_{\mathrm{x}}(\mathrm{RE}=\mathrm{Nd}, \mathrm{Sm}, \mathrm{Eu}, \mathrm{Tb} ; \mathrm{x}=0,0.05,0.10)$ metallic nanoparticles. Mat Sci Eng B-Solid 112: 188-193.

VARANDA LC, MORALES MP, JAFELICCI M AND SERNA CJ. 2002c. Monodispersed spindle-type goethite nanoparticles from Fe-III solutions. J Mater Chem 12: 3649-3653.

VERELST M, OULD-ELY T, AMIENS C, SNOECK E, LECANTE P, MOSSET A, RESPAUD M, BROTO JM AND CHAUDRET B. 1999. Synthesis and characterization of $\mathrm{CoO}, \mathrm{Co}_{3} \mathrm{O}_{4}$, and mixed $\mathrm{Co} / \mathrm{CoO}$ nanoparticles. Chem Mater 11: $2702-2708$.

VIVEK R, BABU VN, THANGAM R, SUBRAMANIAN KS AND KANNAN S. 2013. pH-responsive drug delivery of chitosan nanoparticles as Tamoxifen carriers for effective anti-tumor activity in breast cancer cells. Colloid Surface B 111: 117-123.

VOGT C, TOPRAK MS, MUHAMMED M, LAURENT S, BRIDOT JL AND MULLER RN. 2010. High quality and tuneable silica shell-magnetic core nanoparticles. J Nanopart Res 12: 1137-1147.

VONHOENE J, CHARLES RG AND HICKAM WM. 1958. Thermal Decomposition of Metal Acetylacetonates Mass Spectrometer Studies. J Phys Chem 62: 1098-1101. 
WANG C, HOU YL, KIM JM AND SUN SH. 2007. A general strategy for synthesizing FePt nanowires and nanorods. Angew Chem Int Edit 46: 6333-6335.

WANG C, HU YJ, LIEBER CM AND SUN SH. 2008. Ultrathin Au nanowires and their transport properties. J Am Chem Soc 130: 8902-8903.

WANG JJ, ZENG ZW, XIAO RZ, XIE TA, ZHOU GL, ZHAN XR AND WANG SL. 2011. Recent advances of chitosan nanoparticles as drug carriers. Int J Nanomed 6: 765-774.

WANG ZL, YIN JS, MO WD AND ZHANG ZJ. 1997. In-situ analysis of valence conversion in transition metal oxides using electron energy-loss spectroscopy. J Phys Chem B 101: 6793-6798.

WEI H ET AL. 2017. Exceedingly small iron oxide nanoparticles as positive MRI contrast agents. Proc Natl Acad Sci USA 114: 2325-2330.

WEI SY, WANG Q, ZHU JH, SUN LY, LIN HF AND GUO ZH. 2011. Multifunctional composite core-shell nanoparticles. Nanoscale 3: 4474-4502.

WU LH, MENDOZA-GARCIA A, LI Q AND SUN SH. 2016a. Organic Phase Syntheses of Magnetic Nanoparticles and Their Applications. Chem Rev 116: 10473-10512.

WU Z, YANG S AND WU W. 2016b. Shape control of inorganic nanoparticles from Solution. Nanoscale 8: 1237-1259.

YAO HB, FAN MH, WANG YJ, LUO GS AND FEI WY. 2015. Magnetic titanium dioxide based nanomaterials: synthesis, characteristics, and photocatalytic application in pollutant degradation. J Mater Chem A 3: 17511-17524.

YIN DY, LI XL, MA YY AND LIU Z. 2017. Targeted cancer imaging and photothermal therapy via monosaccharide-imprinted gold nanorods. Chem Commun 53: 6716-6719.

YIN Z, ZHU J, HE Q, CAO X, TAN C, CHEN H, YAN Q AND ZHANG H. 2014. Graphene-based materials for solar cell applications. Adv Energy Mater 4: 1300574.

YOFFE S, LESHUK T, EVERETT P AND GU F. 2013. Superparamagnetic Iron Oxide Nanoparticles (SPIONs): Synthesis and Surface Modification Techniques for use with MRI and Other Biomedical Applications. Curr Pharm Design 19: $493-509$.

YOKSAN R, JIRAWUTTHIWONGCHAI J AND ARPO K. 2010. Encapsulation of ascorbyl palmitate in chitosan nanoparticles by oil-in-water emulsion and ionic gelation processes. Colloid Surface B 76: 292-297.

ZACHARAKI E, KALYVA M, FJELLVAG H AND SJASTAD AO. 2016. Burst nucleation by hot injection for size controlled synthesis of epsilon-cobalt nanoparticles. Chem Cent J 10: 10.

ZENG LY, WU D, ZOU RF, CHEN TX, ZHANG JC AND WU AG. 2018. Paramagnetic and Superparamagnetic Inorganic Nanoparticles for T-1-Weighted Magnetic Resonance Imaging. Curr Med Chem 25: 2970-2986.

ZHANG RY, KHALIZOV A, WANG L, HU M AND XU W. 2012. Nucleation and Growth of Nanoparticles in the Atmosphere. Chem Rev 112: 1957-2011. 